\title{
6-(7-nitro-2,1,3-benzoxadiazol-4-ylthio) hexanol ameliorates the progression of endometriosis by regulating GSTM4 expression to inhibit proliferation and induce apoptosis
}

Wei Liu

Shanxi Bethune Hospital

$\mathrm{Na}$ Zhang

Shandong Provincial Hospital

Yanbo Du

Shandong University Cheeloo College of Medicine

Xiaoqiang Liu

Qingdao Women and Children's Hospital

Jinlong Ma

Shandong University Cheeloo College of Medicine

Lei Yan ( $\nabla$ yanlei@sdu.edu.cn )

Shandong University Cheeloo College of Medicine https://orcid.org/0000-0001-6548-1317

\section{Research}

Keywords: GSTM41, NBDHEX2, endometriosis3, proliferation4, apoptosis5, Nrf26

Posted Date: September 7th, 2021

DOl: https://doi.org/10.21203/rs.3.rs-861230/v1

License: (c) (i) This work is licensed under a Creative Commons Attribution 4.0 International License.

Read Full License 


\section{Abstract}

Background: Endometriosis is a chronic disease associated with disorder of the oxidative balance and chronic inflammation. Although endometriosis is a benign disease, it has the characteristics properties similar to malignant cancer.

Methods: The present study aim to investigate the role of glutathione S-transferase Mu class 4 (GSTM4), and tested if 6-(7-nitro-2,1,3-benzoxadiazol-4-ylthio) hexanol (NBDHEX) could regulate GSTM4 expression to affect cell proliferation, migration, invasion and apoptosis in endometriosis. Expression of GSTM4 was detected by immunohistochemistry in 15 cases of endometriosis patients and compared with 15 healthy controls. Primary endometrial cells were analyzed by western blotting (WB) to determine expression of GSTM4, PCNA, MMP-9, Survivin, Bcl-xl, Bax, Keap1 and Nrf2. CCK8 and transwell assays were used to study the effects of GSTM4 and NBEHEX on endometrial cells. The effect on apoptosis was analysised by flow cytometry.

Results: The expression of GSTM4 was significantly increased in endometriosis than those from controls $(p<0.01)$. The results suggested that NBDHEX negatively regulates GSTM4 expression, induces cell proliferation, migration, invasion, and promotes cell apoptosis. NBDHEX decreased the expression of GSTM4 ( $<<0.05)$, PCNA $(p<0.05)$, MMP-9 $(p<0.01)$, Survivin $(p<0.05)$ and Bcl-xI $(p<0.05)$, along with increased expression of Bax $(p<0.05)$. The results also showed that NBDHEX decreased the expression of Nrf2 ( $p<0.05)$, but had no effect on the expression of Keap1( $p>0.05)$. After transfection with si-GSTM4, the protein level was down-regulated by nearly $70 \%(p<0.05)$. Silencing of GSTM4 depressed the proliferation, migration, invasion and gene expression of endometrial stromal cells in patients with endometriosis and controls. Knockdown of GSTM4 interacting with Nrf2 induced apoptosis by decreasing the expression of Survivin $(p<0.05), B c l-x l(p<0.05)$ and increasing the expression of Bax $(p<0.05)$, but it did not affect the expression of Keap1 $(p>0.05)$ in endometriosis and controls.

Conclusions: Inhibition of GSTM4 by NBDHEX suppresses the cell viability growth, migration, invasion and interact with Nrf2 to induce apoptosis, but has no effect on the expression of Keap1 in endometriosis. The use of siRNA to knockdown GSTM4 more accurately confirmed its ability to ameliorate the progression of endometriosis. NBDHEX may have therapeutic potential in the treatment of endometriosis.

\section{Introduction}

Endometriosis is a chronic disease caused by the presence of endometrial glands and stroma in ectopic locations, including ectopic pelvic peritoneum, ovary, fallopian tubes, broad ligament, abdomen, rectovaginal septum and some time even to lungs. It is usually associated with dysmenorrhea, dyspareunia, chronic pelvic pain, and infertility[1, 2]. Although endometriosis is a benign disease, it has the characteristics properties similar to malignant cancer.The common therapies for treatment of endometriosis include medication and surgery[3]. Medication is appropriate for most patients with 
endometriosis. The first-line therapy for drug treatment include oral contraceptive pills or nonsteroidal anti-inflammatory drugs[4]. However, with these therapeutic approaches, many patients have had little efficacy, or only short-term remission, and some patients even get worse. The mechanism underling endometriosis progression is not fully understood, but several studies demonstrated that it is associated with disorder of the oxidative balance[5, 6]. Oxidative stress is resulted from unbalanced production of reactive oxygen species (ROS) and the cell's own antioxidant defense. Cancer stem cells proliferate spontaneously takeing the advantage of the aberrant redox system[7]. In addition, the imbalance of immune system resulting in the accumulation of inflammatory factors is also one of the pathogenesis of endometriosis[8]. In order to find a better therapy for endometriosis, we urgently need to find new and effective drugs to treat this disease.

Based on the biochemical, immunologic, and structural properties, GSTs have been placed into seven classes of cytosolic proteins, the most commom ones are the Alpha, Mu, and Pi classes[9].Human GSTM4 gene was first isolated from cervical carcinoma cell line HeLa and the protein forms functional dimers was comprised of 218 amino acids with a $M_{r}$ of approximately $26.4 \mathrm{kDa}[10]$. The genes for GSTM4 is located on chromosome 1 and contains eight exons and seven introns[11, 12]. The GST Mu family consist of at least six expressed isozyme subunits, GSTM1-6, which have 70-90\% amino acid sequence identity. Despite the high level of amino acid sequence identity, the enzymatic properties of these enzymes were quite different[10]. We used tandem mass tags combined with multidimensional liquid chromatography and mass spectrometry analyses to screen the proteomic profiles of endometrial tissues from endometriosis patients and healthy women. Acquired data revealed that GSTM4 was highly expressed in endometriosis patients.

NBDHEX was reported to be synthesized by Ricci et al in 2005[13]. A study specifically targeting GSTM4 has found that NBDHEX was used to inhibit the pharmacological activity of GSTM4 and significantly limited cellular proliferation and oncogenic transformation in Ewing sarcoma cells. The combination of NBDHEX and etoposide may increase cytotoxicity, suggesting that GSTM4 may act as an inhibitor of apoptosis[14]. This compound is a representative molecule of a new class of 7-nitro-2,1,3-benzoxadiazole (NBD) derivatives, which can inhibit GSTs catalytic activity and induces apoptosis of tumor cells. Lots of evidence emphasizes that NBDHEX can be used as a new potential anticancer agent and is effective against drug-resistant tumors overexpressing[15, 16].

Nuclear factor-erythroid 2-related factor 2 (Nrf2) is an important regulator of cellular apoptosis via inducing oxidative stress in different cell types. It encodes phase II metabolic enzymes related to detoxification, which are involved in the detoxification of various carcinogens, environmental toxins, drugs, physiological products of oxidative stress, etc[17]. Inhibition of Nrf2 promotes apoptosis and oxidative stress in multiple myeloma[18]. A research conclude that elevated hepatic iron in a mouse model activates NRF2 inducing expression of phase I/II proteins, such as GSTM1, GSTM4, and NAD(P)H dehydrogenase quinone 1[19]. 
The present study aim to investigate the role of GSTM4, and tested if NBDHEX could modulate GSTM4 expression to affect cell proliferation, migration, invasion and apoptosis in endometriosis.

\section{Materials And Methods}

\section{Patients and sample collection}

This study recruited nonpregnant women of reproductive age (20-46 years) at the Shandong provincial Hospital and Reproductive Hospital Affiliated to Shandong University from January 2017 to January 2019. The classification of endometriosis is referred to American Society of Reproductive Medicine (ASRM) revised classification[20]. 15 cases of human eutopic endometrial tissues of ovarian endometriosis for immunohistochemical was collected from patients who undergoing laparoscopic diagnosed as endometriosis and then confirmed by histological examination. As for the healthy control group, 15 cases of normal endometrial tissues were obtained from patients with tubal factors. Another 9 cases of fresh endometrial eutopic tissues were collected during the proliferative phase of the menstrual cycle as the experimental group and 9 cases of endometrial tissues who underwent oviduct obstruction were collected as the controls to isolate and culture primary endometrial stromal cells for subsequent experiments. These samples were collected from October 2019 to October 2020. Both the endometriosis and control groups of women did not receive hormonal treatments for 3 months prior to surgery. The studies involving human participants were approved by Institutional Review Board of the Reproductive Hospital Affiliated to Shandong University (registration number 2020-14). Written informed consent for participation was obtained from patients before surgery.

\section{Immunohistochemical staining}

Xylene dewaxing, a series of concentration gradient of alcohol hydration, EDTA repair antigen, endogenous peroxidase blocker eliminate endogenous non-specific peroxidase activity, quickblock blocking buffer block non-specific protein binding for 30 minutes. Subsequently, the samples were incubated with GSTM4 antibody (1:100 dilution, Proteintech, China) overnight at $4^{\circ} \mathrm{C}$. After washing in PBS for three times, the samples were incubated with enhanced enzyme labeled goat anti rabbit IgG polymer at $37^{\circ} \mathrm{C}$ for $20 \mathrm{~min}$. The slides were dyed with $\mathrm{DAB}$ agent for 5-10 min and counterstained in hematoxylin for 3 min. Finally, immunohistochemistry images were captured using an Olympus 1X51 microscope (Japan). Immunohistochemical staining was performed using the two-step rabbit detection kit (ZSGB-BIO pv-9001, China).

\section{Isolation and culture of primary human endometrial stromal cells}

Primary human endometrial stromal cells were isolated by digesting the fresh tissue fragments with $0.1 \%$ collagenase type I (Gibco, USA). Briefly, fresh endometrial tissues were washed with $10 \mathrm{ml}$ of pre-warmed sterile PBS three times to remove blood and minced into small pieces using ophthalmic scissors and incubated with $0.2 \%$ type I collagenase in a water bath for $40-50 \mathrm{~min}$ at $37^{\circ} \mathrm{C}$. The collagenase activity 
was terminated by adding three times the volume of PBS. The tissue suspension was first filtered through a $100-\mu \mathrm{m}$ monofifilament nylon mesh, then filtered through a $38.5-\mu \mathrm{m}$ monofifilament nylon mesh and centrifuged at $1000 \mathrm{rmp}$ for $5 \mathrm{~min}$. The stromal cells were subsequently cultured in phenol red-free DMEM/F12 (1:1) (Life Technologies, Gibco, USA) supplemented with 20\% fetal bovine serum (FBS; BI, Israel), $1 \%$ penicillin and $1 \%$ streptomycin in a incubator with $5 \% \mathrm{CO} 2$ atmosphere at $37^{\circ} \mathrm{C}$. Culture medium was exchanged every 2 days. The first passage cells were used for the subsequent experiments, and the passage number of cells used in all experiments were less than 5 . The purity of stromal cells has been verified in our group's previous papers[21].

\section{Cell Transfection Assay And Cell Treatments}

GSTM4 small interfering RNA (siRNA) and negative control siRNA (si-NC) were purchased from Shanghai GenePharma (China). The sense sequence of GSTM4 siRNA (GSTM4-homo 110 siRNA) was 5'GCUCCUGACUAUGACAGAATT-3', and the antisense was 5'-UUCUGUCAUAGUCAGGAGCTT-3'. Endometrial stromal cells were seeded in 6-well plates, cultured to $70-80 \%$ density, and transfected with the above siRNA using lipofectamine 3000 (Invitrogen, USA) according to the manufacturer's protocol. The transfection mixture was changed after 10 hours with DMEM/F12 with $20 \%$ FBS. Cells were harvested after 48 hours for western blot and other assays.

\section{NBEHEX treatment of primary endometrial stromal cells}

NBDHEX was dissolved in DMSO at a $10 \mathrm{mM}$ concentration (MecChemExpress, USA) and stock solution aliquots were stored in darkness at $-80^{\circ} \mathrm{C}$. The treatment concentrations ranges were determined according to the manufacturer's instructions and published papers. Immediately before use, NBEHEX was diluted to their working concentration required for the in vitro experiments with serum-free DMEM/F12. The final concentration of DMSO never exceeded $0.1 \%$, and this dose had no cytotoxic effect on our cells. Primary endometrial stromal cells were treated with appropriate concentration of NBDHEX for $48 \mathrm{~h}$.

\section{Cell counting kit-8 experiments}

Cell Counting Kit-8 (CCK8; Beyotime,China) was used to assess cell viability according the manufacturer's instructions. Primary endometrial stromal cells were seeded in 96-well plates at a density of $2 \times 10^{3}$ cells/well. Following specific drug addition, the cells were cultured for 48 hours. CCK8 solution was supplemented with $10 \mu$ lo each well and incubated in dark for 2 hours at $37 \circ \mathrm{C}$. A microplate reader was used to measure color change at $450 \mathrm{~nm}$, and the absorbance (optical density value) was observed to be directly proportional to cell viability. For transfected cells, each group with three replicate wells. It was incubated for $0,24,48$ and 72 hours, with $10 \mu$ to each plate and incubated for 2 hours at $37^{\circ} \mathrm{C}$ in the dark. The OD value was observed to be directly proportional to cell viability and growth curves were drawn.

\section{Transwell migration and invasion assays}


In vitro transwell migration and invasion assays were performed using a 24-well plates with $8 \mu \mathrm{m}$ pore size inserts (Corning, USA) according to the manufacturer's protocols. For migration assay, endometrial stromal cells were implanted into the upper surface of tanwell chambers after 48 hours of transfection or drug treatment. In the upper surface, Cells $\left(1 \times 10^{5}\right)$ were seeded in $200 \mu$ l of serum-free phenol red-free DMEM/F12, while $600 \mu$ l of phenol red-free DMEM/F12 culture medium containing $10 \%$ FBS was added into the bottom chamber. For invasion assay, matrigel $(1 \mathrm{mg} / \mathrm{mL}, \mathrm{BD}$ Biosciences, USA) was diluted with DMEM/F12 in the ratio of 1:8. $50 \mu \mathrm{L}$ of each well was evenly coated on the upper chamber on the each transwell chamber and incubated in $37^{\circ} \mathrm{C}$ for 2 hours. Endometrial stromal cells were seeded into the upper surface of tanwell chambers with $200 \mu \mathrm{L}$ of serum-free medium and allowed to invade the lower chamber, which contained $600 \mu \mathrm{l}$ of DMEM/F12 culture medium containing $10 \%$ FBS. To evaluate the migration and invasion potential, cells were allowed culture for a period of 24 and 48 hours in culture, respectively. The numbers of cells invaded into matrigel on the bottom chamber and cells migrated to the other side of the insert were counted in eight random fields and averaged.

After indicated time, the cells on the upper surface of the chambers that did not migrate or invade were removed by wiping with cotton swabs. Cells invaded into matrigel on the bottom chamber and cells migrated to the other side of the insert were fixed in $4 \%$ paraformaldehyde for 20 min, permeated in methanol for $20 \mathrm{~min}$, stained with hematoxylin for another $20 \mathrm{~min}$ and fixed on a glass slide. The number of cells on the underside of the chambers were observed and counted under the Olympus 1X51 microscope(Japan) in three random fields.

\section{Protein extraction and western blot analysis}

Cultured cells were washed with cold PBS three times. For total protein extraction, the radioimmunoprecipitation assay(RIPA) buffer (Shanghai, China) and protease/phosphatase inhibitor cocktail(Cell Signaling Technology, USA) were mixed in a ratio of $99: 1$, and $100 \mu \mathrm{l}$ of mixture was added to each $10 \times 10^{6}$ cells lysed on ice for $30 \mathrm{~min}$. The cells were scraped and centrifuged at $12,000 \times \mathrm{g}$ at $4 \circ \mathrm{C}$ for $15 \mathrm{~min}$. The supernatant was the extracted protein, which was transferred to another $1.5 \mathrm{ml}$ microcentrifuge tube, diluted in 5×SDS-PAGE sample loading buffer and boiled for 15 minutes. The protein concentration was determined by BCA protein assay kit (Thermo Scientific, USA).

For nuclear protein extraction, we used Minute cytoplasmic and nuclear extraction kit for cells (Invent Biotechnologies,USA) according to the manufacturer's introduction. Add $100 \mu$ l cytoplasmic extraction buffer per 6-well plate, cultured on ice for $5 \mathrm{~min}$. The lysed cells were scrape with a transfer pipette, and transferred to pre-chilled $1.5 \mathrm{ml}$ microcentrifuge tube and vibrated violently for 15 seconds. Centrifuge the tube at $16,000 \times \mathrm{g}$ at $4^{\circ} \mathrm{C}$ for $5 \mathrm{~min}$. The supernatant was cytosol fraction. Wash the pellet with cold PBS to reduce contaminnation of cytosolic proteins. Added $50 \mu$ nuclear extraction buffer to the pellet, vortex vigorously for 15 seconds, incubate the tube on ice for $1 \mathrm{~min}$, repeat 4 times. The nuclear extract transferred to a pre-chilled filter cartridge with collection tube and centrifuge at $16,000 \times \mathrm{g}$ at $4^{\circ} \mathrm{C}$ for 30 seconds and discard the fillter cartridge. The rest is the same as the total protein extraction. 
The protein was separated by $10 \%$ sodium dodecylsulphate-polyacrylamide gel electrophoresis, and then transfered to a PVDF (polyvinylidene diffluoride) membrane. After blocking in $5 \%$ non-fat milk at room temperature for $60 \mathrm{~min}$, the membrane was incubated in a refrigerator overnight at $4^{\circ} \mathrm{C}$ with the primary antibody. After washing with tris-buffered saline-tween (TBST) for 10 min three times, the membrane were incubated for $60 \mathrm{~min}$ at room temperature with corresponding secondary. Primary antibodies against rabbit anti-human GSTM4 (1:500 dilution, Proteintech, China), Kelch-like ech-associated protein 1 (Keap1), Nrf2, Bax, MMP9(1:1000 dilution, Cell Signaling Technology, USA), and mouse anti-human $\beta$ Actin, PCNA, Lamin B (1:5000 dilution, Proteintech, China)were used. Goat anti-rabbit and Goat antimouse HRP-conjugated secondary antibodies were obtained from Proteintech (1:10000 dilution, China).

\section{Apoptosis analysis by flow cytometry}

Apoptosis was evaluated using Annexin V-APC/7AAD apoptosis kit (MultiSciences Biotech, China). Endometrial cells treated with NBDHEX or transfected with si-RNA as previously described were double stained with Annexin V-APC and 7-AAD, according to the manufacturer's instruction. Cell apoptosis was detected by flow cytometry (BD Bio- sciences, USA). Briefy, the collected cells were resuspended in 500ul binding buffer. Then $5 \mu$ l Annexin V-APC and $10 \mu \mathrm{l}$ 7-AAD were added and mixed for 5-10 min without light. Cell-associated fluorescence was analyzed by flow cytometry. The percentage of apoptotic positive cells including early apoptotic (annexin V-positive) and late apoptotic (Annexin V and 7-AAD-positive) cells.

\section{Statistical analysis}

Statistical analyses were performed using GraphPad Prism 7.0 software. Values were expressed as means \pm standard deviation (SD). Comparisons between two groups were performed using Student's ttests. Anova followed by Newman-Keuls tests were used to compare differences among multiple groups. Image $\mathrm{J}$ software was used to count positive immunohistochemical signals, and the results were represented by optical density. $\mathrm{P}<0.05$ was considered statistically signifificant. Each experiment was repeated three times.

\section{Results}

\section{GSTM4 protein expression and localization in endometrial stromal cells from endometriosis patients}

To evaluate the protein expression of GSTM4 on endometriosis, we first performed immunohistochemistry staining to detect the protein expression level of endometrial cells between 15 eutopic endometrial samples from patients with ovarian endometriosis and 15 control endometrial samples from woman without endometrisis. We found that GSTM4 is mainly expressed in cytoplasm of stromal cells and glandular epithelial cells in endometrial tissues. The expression levels of GSTM4 was significantly increased in eutopic endometrial lesions from patients with ovarian endometriosis than those from controls $(0.205 \pm 0.013$ vs. $0.291 \pm 0.014$, $P<0.001$; Fig. $1 \mathrm{~A})$. The immunocytochemical 
staining results were represented by optical density (Fig. 1B). WB also detected that the protein levels of GSTM4 were increased in the eutopic endometrium compared to control endometrium $(0.899 \pm 0.090$ vs. $1.371 \pm 0.121 . p<0.01$; Fig. $1 \mathrm{C})$. Densitometric analysis was used to calculate representative quantitative data (Fig. 1D). Taken together, the data suggested that increased expression of GSTM4 might involved in the pathological process in patients with endometriosis.

\section{Inhibition of GSTM4 by NBDHEX suppresses the cell viability growth, migration, invasion of endometrial stromal cells from endometriosis patients}

Although endometriosis is not a malignant disease, it has its own unique characteristics, but it also has similar characteristics with tumor cells, such as growth, migration, and invasion. In order to determine the mechanism of NBDHEX inhibiting the formation of endometriosis, we studied the effect of NBDHEX on the proliferation of human primary endometrial stromal cells from endometriosis patients. NBDHEX is an effective GSTs inhibitor. We treated primary endometriosis cells with different doses of NBDHEX $(0.25$ $\mu \mathrm{M}, 0.5 \mu \mathrm{M}, 0.75 \mu \mathrm{M}, 1 \mu \mathrm{M}, 1.5 \mu \mathrm{M}, 2 \mu \mathrm{M}, 2.5 \mu \mathrm{M}, 3 \mu \mathrm{M}, 3.5 \mu \mathrm{M}$ and $4 \mu \mathrm{M})$. According to CCK8 assay, the absorbance value of each inoculated cell well was measured. The higher the absorbance value, the more viable cells. We found that cell proliferation decreased in a dose-dependent manner after 48 hours of drug treated (Fig. 2A). The cell survival rate of the $0 \mu \mathrm{M}$ drug treatment well was set as 1 , and the ratio of the absorbance value of other concentrations to the $0 \mu \mathrm{M}$ drug well was the relative survival rate. We fitted the dose-survival curve through Prism 7.0 and calculated the IC50 value of the drug. The result showed that IC50 values were about $1.44 \mu \mathrm{M}$ for primary endometrial cells (Fig. 2B).

We also assessed the difference effect of $0 \mu \mathrm{M}, 0.75 \mu \mathrm{M}$ and $1.5 \mu \mathrm{M}$ NBDHEX treatment on migration and invasion of endometrial cells. The cells on the lower surface of the membrane were counted. The result showed that migration and invasion were significantly reduced in $1.5 \mu \mathrm{M}$ NBDHEX group compared to the $0 \mu \mathrm{M}$ NBDHEX group. With the increase of NBDHEX concentration, the migration ability of cells decreased (Fig. 2C). There was no significant difference between $0 \mu \mathrm{M}$ NBDHEX group and $0.75 \mu \mathrm{M}$ NBDHEX group $(238.3 \pm 21.25$ vs. $183.3 \pm 22.94, p>0.05)$, and there was significant difference between 0 $\mu \mathrm{M}$ NBDHEX group and $1.5 \mu \mathrm{M}$ NBDHEX group $(238.3 \pm 21.25$ vs. $128.1 \pm 21.98, \mathrm{P}<0.001)$. In the invasion assay, the higher the concentration of NBDHEX, the weaker the invasion ability of cells (Fig. 2D). There were significant differences between $0 \mu \mathrm{M}$ NBDHEX group and $0.75 \mu \mathrm{M}$ NBDHEX group groups $(154.2 \pm$ 9.181 vs. $78.67 \pm 7.315, \mathrm{P}<0.0011), 0 \mu \mathrm{M}$ NBDHEX group and $1.5 \mu \mathrm{M}$ NBDHEX group(154.2 $\pm 9.181 \mathrm{vs}$. $44.67 \pm 3.765, P<0.001)$.

Based on the above experiments, we chose NBDHEX concentration of $0 \mu \mathrm{M}$ and $1.5 \mu \mathrm{M}$ to treat the eutopic endometrial stroma cells to explore the effects on proliferation, migration and invasion. Western blot analysis was used to detect the changes of PCNA and MMP-9 protein levels (Fig. 2E). Expression of $\mathrm{PCNA}(2.487 \pm 0.374$ vs. $1.193 \pm 0.374, \mathrm{p}<0.05)$ and MMP-9(3.153 \pm 0.590 vs. $1.383 \pm 0.085, p<0.05)$ were significantly reduced in $1.5 \mu \mathrm{M}$ NBDHEX group compared to the $0 \mu \mathrm{M}$ NBDHEX group.

Inhibition of GSTM4 by NBDHEX induces apoptosis in endometrial stromal cells from endometriosis patients

Page $8 / 26$ 
To further evaluate the inhibitor of GSTM4 by NBDHEX mediated cell death of eutopic endometrial stroma cells, the effect of NBDHEX on apoptosis was detected by Annexin V-APC/7-AAD apoptosis kit. Apoptosis and the total apoptotic rate of cells of NBFHEX exposure are shown in Fig. 3A. In $0 \mu \mathrm{M}$ NBDHEX group, the cell survival rate was $78.16 \%$. However, in $1.5 \mu \mathrm{M}$ NBDHEX group apoptosis rate was increased by about $13.01 \%(P<0.05)$. Then the apoptosis related protein levels of Survivin, Bcl-xl and Bax were measured by western blot analysis (Fig. 3B). Compared with $0 \mu \mathrm{M}$ NBDHEX group, Survivin (3.162 \pm 0.690 vs. $1.175 \pm 0.112, p<0.05)$ and $\mathrm{Bcl}-\mathrm{XL}(2.529 \pm 0.588$ vs. $1.363 \pm 0.613, p<0.01)$ protein levels were significantly decreased in the $1.5 \mu \mathrm{M}$ NBDHEX group, while $\operatorname{Bax}(2.257 \pm 0.504$ vs. $3.019 \pm 0.598, p<0.05)$ protein levels were increased.

\section{Inhibition of GSTM4 by NBDHEX interacting with Nrf2 induces apoptosis, but it did not affect the expression of Keap1 in endometrial stromal cells from endometriosis patients}

Nrf2 is an important regulator of cellular apoptosis via inducing oxidative stress in different cell types. In order to further elucidate the role of GSTM4 in the progression of endometriosis, we detected the protein expression levels of Keap1 and Nrf2 and its downstream related gene in endometriosis. We first compared the protein expression of Keap1, Nrf2 and GSTM4 in endometriosis patients and controls (Fig. 4A). WB results showed that compared with the control group, Keap1 decreased ( $2.310 \pm 0.286$ vs. $1.517 \pm 0.114, p<0.05)$, Nrf2 increased $(1.500 \pm 0.397$ vs. $2.313 \pm 0.236, p<0.05)$ and GSTM4 increased $(1.463 \pm 0.203$ vs. $3.283 \pm 0.090, p<0.01)$ in the experimental group.

We hypothesized that NBDHEX treatment did not change the expression of Keap1 and Nrf2, but changeed the expression of GSTM4, indicating that GSTM4 was downstream of Keap1/Nrf2 signaling pathway. As show in Fig. 4B, WB results demonstrated that $1.5 \mu \mathrm{M}$ NBDHEX group could reduce the expression of GSTM4 compared to the $0 \mu \mathrm{M}$ NBDHEX group $(2.429 \pm 0.233$ vs. $1.449 \pm 0.092, \mathrm{p}<0.01)$. However, WB results also showed that NBEHEX had no effect on the expression of Keap1 (1.363 \pm 0.613 vs.1.371 \pm $0.531, p>0.05)$, but the expression of Nrf2 was decreased (3.49 \pm 0.422 vs. $1.772 \pm 0.659, p<0.05$ ) compared to the $0 \mu \mathrm{M}$ NBDHEX group. We consider that Nrf2 and GSTM4 may inhibit each other, that is, Nrf2 expression decreases and GSTM4 expression is inhibited, which is consistent with the common theory. However, NBDHEX inhibited GSTM4 expression, further inhibited Nrf2 expression and promoted apoptosis.

Knockdown of GSTM4 depress the cell proliferation, migration and invasion both in eutopic endometrial stroma cells with endometriosis and control endometrial stroma cells

Because in addition to inhibiting the expression of GSTM4, NBDHEX may also inhibit the expression of other GSTs family proteins. In order to further elucidate the role of GSTM4 in the progression of endometriosis, we transfected an siRNA containing an GSTM4 targeting sequence (si-GSTM4) and negative control siRNA (si-NC) in eutopic endometrial stroma cells with endometriosis and control endometrial stroma cells. 
When the cells were not transfected with si-GSTM4, the expression of GSTM4 in the eutopic group was about $60 \%$ higher than that in the control group $(1.337 \pm 0.152$ vs. $3.306 \pm 0.634, P<0.001)$. After cells transfected with si-GSTM4, GSTM4 protein level was down-regulated by nearly 70\% in eutopic group (3.306 \pm 0.634 vs. $0.987 \pm 0.206, p<0.001)$ and down-regulated by $68 \%$ in control group $(1.337 \pm 0.152$ vs. $0.426 \pm 0.309, p<0.05)$. (Fig. $5 A)$

Silencing of GSTM4 led to proliferation inhibition of both group as assessed by CCK8 assay. The absorbance of the cells in each inoculated cell well at $450 \mathrm{~nm}$ was detected by enzyme-labeled analyzer. The results showed that the absorbance of the cells increased with the prolonging of culture time. The proliferation of endometriosis cells was stronger than that in the control group. After knockdown of GSTM4, the proliferation ability of cells in both groups was decreased compared with that in si-NC group(Fig. 5B).

Endometriosis cells and normal endometrial cells were cultured for 36 hours with and without si-GSTM4 and then assessed by transwell migration and invasion assay. When without si-GSTM4 transfection, the number of migration(170.3 \pm 8.352 vs. $271.7 \pm 9.854, p<0.001)$ and invasion cells $(100.4 \pm 3.473$ vs. $139.0 \pm 7.297, p<0.001)$ in the endometriosis group was significantly higher than that of the control group. After transfected with si-GSTM4 the number of migration cells(170.3 \pm 8.352 vs. $125.3 \pm 8.162, p<$ $0.05 ; 271.7 \pm 15.460$ vs. $145.2 \pm 9.854, p<0.001)$ and the number of invasion cells $(100.4 \pm 3.473$ vs. $43.11 \pm 3.048, p<0.001 ; 139.00 \pm 7.297$ vs. $67.89 \pm 5.184 p<0.001$ ) were significantly reduced in control group and eutopic group(Fig. 5C and D).

Additionally, we used western blot analysis to detect the changes of PCNA and MMP-9 protein levels. When without si-GSTM4 transfection, the protein levels of PNCA and MMP-9 also compared between endometrial cells and normal endometrial cells. The results showed that the expression levels of PCNA(1.457 \pm 0.282 vs. $2.21 \pm 0.310, p<0.05)$ and MMP-9 $(1.190 \pm 0.148$ vs. $1.753 \pm 0.217, p<0.01)$ were higher in eutopic endometrial stroma cells compared to the control group. After transfected with siGSTM4, The protein expression level of PCNA (2.21 \pm 0.310 vs. $1.437 \pm 0.185, p<0.05)$ in endometriosis cells was significantly decreased. While the expression of PCNA $(1.457 \pm 0.282$ vs. $1.187 \pm 0.150, p>0.05)$ in normal endometrial cells was also decreased, but there was no statistical difference. Expression of MMP-9 (1.190 \pm 0.148 vs. $0.833 \pm 0.064, p<0.05 ; 1.753 \pm 0.217$ vs. $1.420 \pm 0.066, p<0.05)$ were significantly reduced in two group cells transfected with si-GSTM4. (Fig. 5E).

\section{Knockdown of GSTM4 induces apoptosis both in eutopic endometrial stroma cells with endometriosis and control endometrial stroma cells}

The effect of knockdown of GSTM4 on apoptosis was analysised by flow cytometry. Compared with the control group, apoptosis rate of endometriosis group was statistically significant reduced (33.26 $\pm 5.878 \%$ vs. $19.67 \pm 2.913 \%, p<0.05$ ). When the cells were transfected with si-GSTM4 compared to si-NC, the apoptotic rates were increased both in control group(33.26 \pm 5.878 vs. $51.740 \pm 4.754 \%, p<0.05)$ and eutopic group(19.67 $\pm 2.913 \%$ vs. $36.92 \pm 9.087 \%$, p < 0.05).(Fig. 6A) 
Then the apoptosis related protein levels of Survivin, Bcl-xl and Bax were detected by western blot analysis. When the cells were not transfected with si-GSTM4, the expression levels of the anti-apoptotic proteins Survivin $(2.426 \pm 0.278$ vs. $4.186 \pm 0.728, p<0.01)$ and Bcl-XL $(2.105 \pm 0.147$ vs. $2.779 \pm 0.441, p$ $<0.05$ ) were higher in the eutopic group than those in control group, and the expression levels of proapoptotic protein Bax were lower $(2.257 \pm 0.504$ vs. $1.146 \pm 0.131, p<0.05)$. After cells transfected with siGSTM4, the protein levels of Survivin $(2.426 \pm 0.278$ vs. $0.854 \pm 0.241, p<0.05 ; 4.186 \pm 0.728$ vs. $1.794 \pm$ $0.752, p<0.01)$ and Bcl-xl ( $2.105 \pm 0.147$ vs. $1.244 \pm 0.222 p<0.05,2.779 \pm 0.441$ vs. $1.917 \pm 0.493 p<$ $0.05)$ were significantly decreased, and the protein level of Bax was increased ( $2.257 \pm 0.504 \mathrm{vs} .3 .685 \pm$ $0.708, p<0.05 ; 1.146 \pm 0.131$ vs.2.398 $\pm 0.560, p<0.05$ ) in control group and eutopic group(Fig. 6 B). Therefore, Knockdown of GSTM4 induces apoptosis was involved in the regulation of apoptosis in endometrial stroma cells.

\section{Knockdown of GSTM4 interacting with Nrf2 induces apoptosis, but it did not affect the expression of Keap1 in endometriosis}

We detected the protein expression levels of Keap1, Nrf2 and GSTM4 both in endometriosis and control cells by western blot analysis. The results were similar to those of inhibiting GSTM4 expression by NBDHEX. When the cells were not transfected with si-GSTM4, the protein expression levels of Nrf2 (1.802 \pm 0.267 vs. $2.967 \pm 0.209 P<0.01)$ and GSTM4 $(1.337 \pm 0.152$ vs. $3.306 \pm 0.634 P<0.001)$ were higher in the eutopic group than those in control group, and the expression levels of Keap1 were lower (3.623 \pm 0.265 vs. $2.073 \pm 0.839 p<0.05)$. After cells transfected with si-GSTM4, the protein levels of Nrf2 $(1.802 \pm$ 0.267 vs. $0.935 \pm 0.366, p<0.05 ; 2.967 \pm 0.209$ vs. $2.349 \pm 0.342, p<0.05)$ and GSTM $4(1.337 \pm 0.152$ vs. $0.426 \pm 0.309 p<0.05,3.306 \pm 0.634$ vs. $0.987 \pm 0.206 p<0.001$ ) were significantly decreased, and the protein level of Keap1 $(3.623 \pm 0.265$ vs. $2.817 \pm 0.410 p>0.05,2.073 \pm 0.839$ vs. $1.947 \pm 0.475 p>0.05$ ) have no significant change in control group and endometriosis group (Fig. 7A).

To further confirm the activation of Nrf2 transport into the nucleus, we used nuclear protein to detect the expression of Nrf2 and GSTM4 in cell nucleus of eutopic endometrial stroma cells. Compared with si-NC group, knockdown of GSTM4 decreased Nrf2 level in cell nucleus (1.341 \pm 0.550 vs. $0.896 \pm 0.517 * p=$ $0.0235)$ and total cell $(1.919 \pm 0.199$ vs. $1.405 \pm 0.102 * p=0.0394)$, whereas GSTM4 was not expressed in nucleus (Fig. 7B).

\section{Discussion}

The present study aim to investigate the role of GSTM4, and tested if NBDHEX could modulate GSTM4 expression to affect cell proliferation, migration, invasion and apoptosis in endometriosis. The results demonstrate for the first time that increased GSTM4 expression may be involved in the progression in patients with endometriosis. Inhibition of GSTM4 by NBDHEX suppresses the cell viability growth, migration, invasion and which interacting with Nrf2 induces apoptosis, but it did not affect the expression of Keap1 in endometriosis. The use siRNA to knockdown GSTM4 more accurately confirmed its ability to improve the progression of endometriosis. 
Many studies have reported that the expression level of GST is higher in a number of tumors. The immunocytochemical affirmed that the expression of GSTA, GSTP, GSTM4 and GSTT1 in urothelial cancer cells was stronger than the in benign cells[22]. In Yu Li's study, quantitative proteomics analysis using tandem mass tags (TMTs) coupled with liquid chromatography-mass spectrometry (LC-MS)/MS showed that GSTM4 expression was increased and GSTT1 expression was decreased in psoriasis vulgaris lesional tissues compared with healthy skin tissues[23]. Overexpression of specific GSTMs, GSTM1 and GSTM4 and elevated levels of glutathione contribute to maintaining a reduced state of cytochrome which would decrease apoptosis, thus promoting to methotrexate resistance in human MCF7 breast cancer cells[24]. A report show that GSTM4 is a direct target gene of the EWS/FLI fusion protein. Reduced GSTM4 levels resulted a decrease of oncogenic transformation and a increase of sensitivity of chemotherapeutic agents[25]. GSTM1 expression level was significantly higher in the ectopic and eutopic endometrial of patients with ovarian endometriosis, which could significantly increase cell viability and inhibit cell apoptosis[26]. In this study, for the first time, GSTM4 was found to be highly expressed in endometriosis. Our findings are consistent with above reports, but some studies have shown that the expression of GSTM4 is decreased in some diseases( aging and skin infected with dermatophytes[27, 28].

Although endometriosis is a benign disease, it has the characteristics of migratory and invasive properties similar to malignant cancer[29]. Various phytochemicals like rutin, naringenin, methyl ester of 2-cyano-3,12-dioxooleana-1,9-dien-28-oic acid (CDDO-Me) have been reported for their efficacy against endometriosis[18, 30, 31]. NBDHEX appears to be a promising candidate for targeting and inhibiting GSTs[32]. GSTs displays antiapoptotic activity and is also involved in the cellular resistance to anticancer drugs. A recently published study demonstrates that NBDHEX triggers apoptosis in leukemia cell lines through the dissociation of GSTP1-1 from the GSTP1-1-JNK complex. This event revealed that cancer can be treated by hypothesizing that NBDHEX triggers a crucial perturbation in the GSTs structure[33]. NBDHEX opens up interesting prospects for cancer therapy as a suicide inhibitor of GSTs [14]. One study evaluated the acute toxicity of NBDHEX by a single injection of nbdhex into male BDF1 mice. After 15 days of follow-up, there were no significant changes in body weight, liver weight, spleen weight and red blood cell count. Only a slight increase of white cells, in particular neutrophils, was observed after treatment with NBDHEX[32]. Here, we hypothesized that NBDHEX, being an anti-inflammatory, antiinvasive,pro-apoptotic, could play a therapeutic role in the endometriosis.

We used primary endometrial cells from women with and without endometriosis to deal with the evaluation of therapeutic effect of NBDHEX and exploration of the underlying mechanism using in vitro experimental conditions. We found that cell viability growth decreased in a dose-dependent manner of drug treated. With the increase of NBDHEX concentration, the migration and and invasion ability of cells was decreased. Radhika Kapoor et al. confirmed that MMPs play a important role in the establishment and development of endometriosis. The expression of various prognostic markers such as PCNA, MMP2, MMP9, AKT1 and VEGF in endometral cells certained that endometriosis prevailed in the system[34, 35]. Western blot Analysis detected that PCNA and MMP-9 protein levels were significantly reduced with NBDHEX treatment. Flow cytometry was used to detect the effect of NBDHEX, a GSTM4 inhibitor, on cell 
apoptosis in patients with endometriosis. Treatment of primary endometrial cells from endometriosis patients with NBDHEX, the apoptosis rate was increased by 13.01\%. Apoptosis related protein levels of Survivin, Bcl-xl were significantly decreased, while the protein level of Bax was increased.

The role of Nrf2 transcription factor in the activation of oxidative stress has been demonstrated[36]. It plays an essential role in cytoprotection. Nrf2 resides in the cytoplasm under basal circumstances and formed complexes with Keap1. When exposed to oxidative stress, Keap1 releases Nrf2, which moves to the nucleus, binds to the antioxidant response element (ARE) and associates with Maf protein to induce the expression of cell-protective genes like phase II detoxifying enzymes[37]. Nrf2 is an important regulator of cellular apoptosis via inducing oxidative stress in different cell types. Inhibition of Nrf2 promotes apoptosis and oxidative stress in multiple myeloma[33]. In the livers of male and $\backslash$ or female Nrf2 knockout(KO) mice, the amounts of mRNA for Gstm1, Gstm3 and Gstm4 were reduced to between $3 \%$ and $20 \%$ of that in wild-type (WT) mice .In female WT and female Nrf2 KO mice,The Gstm4\5 polypeptide(s) were expressed higher than genetically equivalent female WT and female Nrf2 KO mice[38]. Microsomal epoxide hyrolase 1 (EPHX1) silencing promoted ACM and MIT induced decrease in cell viability and the apoptosis of human myeloid cells. Nrf2 overexpression significantly increased EPHX1 expression and leukemic cell viability and reduceded leukemic cell apoptosis[39]. A research demonstrated that MLT could protect follicle integrity and prevent apoptosis by activating Nrf2 signaling pathway, increasing the expression of heme oxygenase-1 (HO-1), glutathione S-transferase M1 (GSTM1), SOD and cat, and reducing the levels of ROS, MDA and NO[40]. Some reports suggested that Nrf2 to be activated to supports survival and chemotherapy resistance in multiple myeloma, inhibiting Nrf2 upregulates apoptosis and oxidative stress in multiple myeloma cell lines as well as in patients' samples[41]. Our results demonstrated that NBDHEX could reduce the expression of GSTM4. However, NBEHEX had no effect on the expression of Keap1, but the expression of Nrf2 was decreased. We speculate that NRF2 and GSTM4 may inhibit each other through some mechanism. Nrf2 promotes GSTM4 expression, which is consistent with conventional theory. The specific mechanism by which NBDHEX inhibits the expression of GSTM4 and further inhibits the expression of Nrf2 to promote apoptosis remains to be further studied.

Because of NBDHEX may also inhibits the expression of other GST family proteins, besides to inhibiting the expression of GSTM4. We used primary endometrial cells from women with and without endometriosis to evaluation of effect of GSTM4 and exploration of the underlying mechanism using in vitro experimental conditions. We transfected an si-GSTM4 in endometrial cells to verify the effect of different GSTM4 expression levels on endometriosis. These results suggest that NBDHEX negatively regulates the GSTM4 expression induced proliferation, migration and invasion. The imbalance of oxidative stress has been linked to endometriosis. Keap1 frees Nrf2 in the cytoplasm, and Nrf2 enters the nucleus to induce the expression of Phase II detoxifying enzymes like GSTM4. Nrf2 inhibited apoptosis by altering the expression of Survivin, bcl-xl and bax. After transfected with si-GSTM4, the protein level was down-regulated by nearly $70 \%$. Silencing of GSTM4 depresses the cell proliferation, migration, invasion and gene expression both in endometrial stromal cells from endometriosis patients and that from controls. Knockdown of GSTM4 interacting with Nrf2 induces apoptosis, but it did not affects the 
expression of Keap1 in endometriosis. The anti-apoptotic protein levels of Survivin and Bcl-xl were significantly decreased, and the pro-apoptotic protein level of Bax was increased bith in patients with and without endometriosis. In the future, the endometriosis rat model should be used to verify that NBDHEX alleviates endometriosis by inhibiting GSTM4 expression((Fig. 8).

\section{Conclusion}

In conclusion, the study found that GSTM4 is highly expressed in endometriosis. Inhibition of its expression by NBDHEX can achieve the purpose of alleviating endometriosis, which is the first study to use NBDHEX in the treatment of endometriosis. These results may provide a new thearapy for endometriosis.

\section{Abbreviations}

ASRM

American Society of Reproductive Medicine

DMSO

dimethyl sulfoxide

FBS

fetal bovine serum

GSTM4

glutathione S-transferase Mu class 4

$\mathrm{ICH}$

immunohistochemistry

IC50

half maximal inhibitory

NBDHEX

6-(7-nitro-2,1,3-benzoxadiazol-4-ylthio) hexanol

Nrf2

Nuclear factor-erythroid 2-related factor 2

MLT

melatonin

NQ01

$\mathrm{NAD}(\mathrm{P}) \mathrm{H}$ dehydrogenase quinone 1

OD

optical density

PVDF

polyvinylidene fluoride

ROS

reactive oxygen species 
SiRNA

small interfering RNA

WB

western blotting

\section{Declarations}

\section{Ethics Statement and Consent to participate}

The study was reviewed and approved by the Reproductive Hospital Affiliated to Shandong University (registration number 2020-14). Informed consent was obtained from each patient

\section{Consent for publication}

All the authors agreed to publish the manuscript in Reproductive Biology and Endocrinology.

\section{Availability of data}

All data generated or analyzed during this study are included in this published article and its supplementary information files.

\section{Competing interests}

The authors declare that the research was conducted in the absence of any commercial or financial relationships that could be construed as a potential conflict of interest.

\section{Funding}

This work was supported by the National Natural Science Foundation of China (81571414 and 82071617).

\section{Author Contributions}

LY and NZ contributed to conception and design of the study. WL and XLperformed the experiments. YD and XL performed the statistical analysis. WL and LY wrote the first draft of the manuscript. YD and JM wrote sections of the manuscript. All authors contributed to manuscript revision, read, and approved the submitted version.

\section{Acknowledgments}

Authors wish to thank patients for providing clinical samples and all investigators in this study.

\section{References}


1. Dyson MT, Roqueiro D, Monsivais D, Ercan CM, Pavone ME, Brooks DC, et al Genome-wide DNA methylation analysis predicts an epigenetic switch for GATA factor expression in endometriosis. PLoS Genet. 2014;10(3):e1004158. doi: 10.1371/journal.pgen. 1004158.

2. Macer ML, Taylor HS. Endometriosis and infertility: a review of the pathogenesis and treatment of endometriosis-associated infertility. Obstet Gynecol Clin North Am. 2012;39(4):535 - 49. doi: 10.1016/j.ogc.2012.10.002.

3. Liu W, Sha T, Huang Y, Guo Z, Yan L, Ma J. Factors Influencing the Live Birth Rate Following Fresh Embryo Transfer Cycles in Infertile Women After Endometrioma Cystectomy. Front Med (Lausanne). 2021;8:622087. doi: 10.3389/fmed.2021.622087.

4. Allen C, Hopewell S, Prentice A, Gregory D. Nonsteroidal anti-inflammatory drugs for pain in women with endometriosis. Cochrane Database Syst Rev. 2009;(2):CD004753. doi: 10.1002/14651858.

5. Aghajanova L, Giudice LC. Molecular evidence for differences in endometrium in severe versus mild endometriosis. Reprod Sci. 2011;18(3):229 - 51. doi: 10.1177/1933719110386241.

6. Iwabuchi T, Yoshimoto C, Shigetomi H, Kobayashi H. Oxidative Stress and Antioxidant Defense in Endometriosis and Its Malignant Transformation. Oxid Med Cell Longev. 2015;2015:848595. doi: $10.1155 / 2015 / 848595$.

7. Acharya A, Das I, Chandhok D, Saha T. Redox regulation in cancer: a double-edged sword with therapeutic potential. Oxid Med Cell Longev. 2010;3(1):23-34. doi: 10.4161/oxim.3.1.10095.

8. Izumi G, Koga K, Takamura M, Makabe T, Satake E, Takeuchi A, Taguchi A, et al Involvement of immune cells in the pathogenesis of endometriosis. J Obstet Gynaecol Res. 2018;44(2):191-198. doi: $10.1111 /$ jog. 13559 .

9. Hayes JD, Strange RC. Glutathione S-transferase polymorphisms and their biological consequences. Pharmacology. 2000;61(3):154 - 66. doi: 10.1159/000028396. PMID: 10971201..

10. Comstock KE, Widersten M, Hao XY, Henner WD, Mannervik B. A comparison of the enzymatic and physicochemical properties of human glutathione transferase M4-4 and three other human Mu class enzymes. Arch Biochem Biophys. 1994;311(2):487 - 95. doi: 10.1006/abbi.1994.1266.

11. Comstock KE, Johnson KJ, Rifenbery D, Henner WD. Isolation and analysis of the gene and cDNA for a human Mu class glutathione S-transferase, GSTM4. J Biol Chem. 1993;268(23):16958-65.

12. Zhong S, Spurr NK, Hayes JD, Wolf CR. Deduced amino acid sequence, gene structure and chromosomal location of a novel human class Mu glutathione S-transferase, GSTM4. Biochem J. 1993;291 (Pt 1)(Pt 1):41-50. doi: 10.1042/bj2910041.

13. Ricci G, De Maria F, Antonini G, Turella P, Bullo A, Stella L, et al 7-Nitro-2,1,3-benzoxadiazole derivatives, a new class of suicide inhibitors for glutathione S-transferases. Mechanism of action of potential anticancer drugs. J Biol Chem.2005; 280(28):26397-405. doi: 10.1074/jbc.M503295200.

14. Zhuo R, Kosak KM, Sankar S, Wiles ET, Sun Y, Zhang J, et al Targeting Glutathione S-transferase M4 in Ewing sarcoma. Front Pediatr. 2014;6;2:83. doi: 10.3389/fped.2014.00083.

15. Filomeni G, Turella P, Dupuis ML, Forini O, Ciriolo MR, Cianfriglia M, et al 6-(7-Nitro-2,1,3benzoxadiazol-4-ylthio)hexanol, a specific glutathione S-transferase inhibitor, overcomes the 
multidrug resistance (MDR)-associated protein 1-mediated MDR in small cell lung cancer. Mol Cancer Ther. 2008;7(2):371-9. doi: 10.1158/1535-7163.

16. Turella P, Filomeni G, Dupuis ML, Ciriolo MR, Molinari A, De Maria F, et al A strong glutathione Stransferase inhibitor overcomes the P-glycoprotein-mediated resistance in tumor cells. 6-(7-Nitro2,1,3-benzoxadiazol-4-ylthio)hexanol (NBDHEX) triggers a caspase-dependent apoptosis in MDR1expressing leukemia cells. J Biol Chem. 2006;281(33):23725-32. doi: 10.1074/jbc.M604372200.

17. Denson J, Xi Z, Wu Y, Yang $W$, Neale G, Zhang J. Screening for inter-individual splicing differences in human GSTM4 and the discovery of a single nucleotide substitution related to the tandem skipping of two exons. Gene. 2006;379:148 - 55. doi: 10.1016/j.gene.2006.05.012.

18. Kapoor R, Sirohi VK, Gupta K, Dwivedi A. Naringenin ameliorates progression of endometriosis by modulating Nrf2/Keap1/HO1 axis and inducing apoptosis in rats. J Nutr Biochem. 2019;70:215226. doi: 10.1016/j.jnutbio.2019.05.003.

19. Moon MS, McDevitt El, Zhu J, Stanley B, Krzeminski J, Amin S, et al Elevated hepatic iron activates NF-E2-related factor 2-regulated pathway in a dietary iron overload mouse model. Toxicol Sci. 2012;129(1): 74-85. doi: 10.1093/toxsci/kfs193.

20. Canis M, Donnez JG, Guzick DS, Halme JK, Rock JA, Schenken RS, et al Revised American Society for Reproductive Medicine classification of endometriosis: 1996. Fertil Steril. 1997;67(5):817 - 21. doi: 10.1016/s0015-0282(97)81391-x.

21. Xu Z, Zhang L, Yu Q, Zhang Y, Yan L, Chen ZJ. The estrogen-regulated IncRNA H19/miR-216a-5p axis alters stromal cell invasion and migration via ACTA2 in endometriosis. Mol Hum Reprod. 2019;25(9):550-561. doi: 10.1093/molehr/gaz040.

22. Oğuztüzün S, Sezgin Y, Yazıcı S, Fırat P, Ozhavzalı M, Ozen H. Expression of glutathione-Stransferases isoenzymes and p53 in exfoliated human bladder cancer cells. Urol Oncol. 2011;29(5):538 - 44. doi: 10.1016/j.urolonc.2009.08.001.

23. Li Y, Lin P, Wang S, Li S, Wang R, Yang L, et al Quantitative analysis of differentially expressed proteins in psoriasis vulgaris using tandem mass tags and parallel reaction monitoring. Clin Proteomics. 2020;17:30. doi: 10.1186/s12014-020-09293-8.

24. Barros S, Mencia N, Rodríguez L, Oleaga $C$, Santos $C$, Noé $V$, et al The redox state of cytochrome $C$ modulates resistance to methotrexate in human MCF7 breast cancer cells. PLoS One. 2013;8(5):e63276. doi: 10.1371/journal.pone.0063276.

25. Luo W, Gangwal K, Sankar S, Boucher KM, Thomas D, Lessnick SL. (2009) GSTM4 is a microsatellitecontaining EWS/FLI target involved in Ewing's sarcoma oncogenesis and therapeutic resistance. Oncogene. 28(46):4126-32. doi: 10.1038/onc.2009.262.

26. Zhao J, Wang L, Li Y, Zhao W, Kang S. Hypomethylation of the GSTM1 promoter is associated with ovarian endometriosis. Hum Reprod. 2019;34(5):804-812. doi: 10.1093/humrep/dez039.

27. Kilic M, Oguztuzun S, Karadag AS, Cakir E, Aydin M, Ozturk L. Expression of GSTM4 and GSTT1 in patients with Tinea versicolor, Tinea inguinalis and Tinea pedis infections: a preliminary study. Clin Exp Dermatol. 2011;36(6):590-4. doi: 10.1111/j.1365-2230.2010.03991.x. 
28. Fu ZD, Csanaky IL, Klaassen CD. Effects of aging on mRNA profiles for drug-metabolizing enzymes and transporters in livers of male and female mice. Drug Metab Dispos. 2012;40(6):1216-25. doi: 10.1124/dmd.111.044461.

29. Bassi MA, Podgaec S, Dias Júnior JA, Sobrado CW, Amico Filho D. N. Bowel endometriosis: a benign disease?. Rev Assoc Med Bras. 2009;55(5):611-6. doi: 10.1590/s0104-42302009000500029.

30. Talebi H, Farahpour MR, Hamishehkar H. (2021) The effectiveness of Rutin for prevention of surgical induced endometriosis development in a rat model. Sci Rep. 2021;11(1):7180. doi: 10.1038/s41598021-86586-4.

31. Siracusa R, D'Amico R, Cordaro M, Peritore AF, Genovese T, Gugliandolo E, et al The Methyl Ester of 2Cyano-3,12-Dioxooleana-1,9-Dien-28-Oic Acid Reduces Endometrial Lesions Development by Modulating the NFkB and Nrf2 Pathways. Int J Mol Sci. 2021;22(8):3991. doi: 10.3390/ijms22083991.

32. Pasello M, Manara MC, Michelacci F, Fanelli M, Hattinger CM, Nicoletti G, et al Targeting glutathione$S$ transferase enzymes in musculoskeletal sarcomas: a promising therapeutic strategy. Anal Cell Pathol (Amst). 2011;34(3): 131 - 45. doi: 10.3233/ACP-2011-012.

33. Turella P, Cerella C, Filomeni G, Bullo A, De Maria F, Ghibelli L, et al Proapoptotic activity of new glutathione S-transferase inhibitors. Cancer Res. 65(9):3751-61. 2005; doi: 10.1158/0008-5472.

34. Tan SH, Pal M, Tan MJ, Wong MH, Tam FU, Teo JW, et al Regulation of cell proliferation and migration by TAK1 via transcriptional control of von Hippel-Lindau tumor suppressor. J Biol Chem. 2009;284(27): 18047-58. doi: 10.1074/jbc.M109.002691.

35. Ricci AG, Olivares CN, Bilotas MA, Meresman GF, Barañao RI. Effect of vascular endothelial growth factor inhibition on endometrial implant development in a murine model of endometriosis. Reprod Sci. 2011;18(7): 614 - 22. doi: 10.1177/1933719110395406.

36. Itoh K. Protective mechanism against oxidative stress by Keap1/Nrf2 pathway. Seikagaku. 78(2):7992. The Journal of Japanese Biochemical Society. 2006;78(2):79-92..

37. Almeida M, Soares M, Ramalhinho AC, Moutinho JF, Breitenfeld L. Prognosis of hormone-dependent breast cancer seems to be influenced by KEAP1, NRF2 and GSTM1 genetic polymorphisms. Mol Biol Rep. 2019;46(3):3213-3224. doi: 10.1007/s11033-019-04778-8.

38. Chanas SA, Jiang Q, McMahon M, McWalter GK, McLellan LI, Elcombe CR, et al Loss of the Nrf2 transcription factor causes a marked reduction in constitutive and inducible expression of the glutathione S-transferase Gsta1, Gsta2, Gstm1, Gstm2, Gstm3 and Gstm4 genes in the livers of male and female mice. Biochem J. 2002;365(Pt 2):405 - 16. doi: 10.1042/BJ20020320.

39. Cheng H, Huang C, Tang G, Qiu H, Gao L, Zhang W, et al Emerging role of EPHX1 in chemoresistance of acute myeloid leukemia by regurlating drug-metabolizing enzymes and apoptotic signaling. Mol Carcinog. 2019;58(5):808-819. doi: 10.1002/mc.22973.

40. Sun TC, Liu XC, Yang SH, Song LL, Zhou SJ, Deng SL, et al Melatonin Inhibits Oxidative Stress and Apoptosis in Cryopreserved Ovarian Tissues via Nrf2/HO-1 Signaling Pathway. Front Mol Biosci. 2020;7: 163. doi: 10.3389/fmolb.2020.00163. 
41. Sun Y, Abdul Aziz A, Bowles K, Rushworth S. High NRF2 expression controls endoplasmic reticulum stress induced apoptosis in multiple myeloma. Cancer Lett. 2018;412:37-45. doi: 10.1016/j.canlet.2017.10.005.

\section{Figures}

Figure 1

A
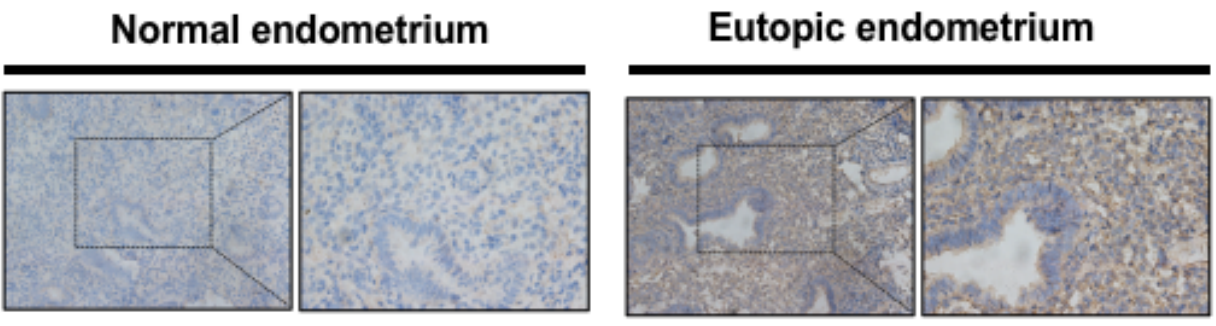

C

GSTM4

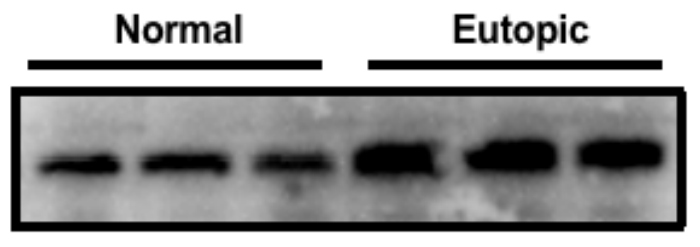

$\beta$-Actin

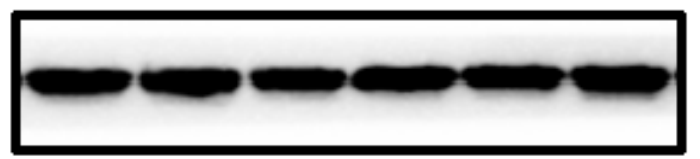

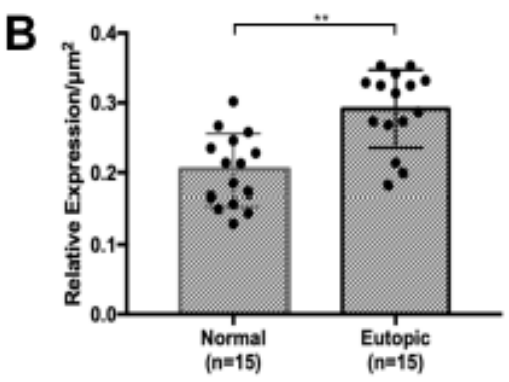

D

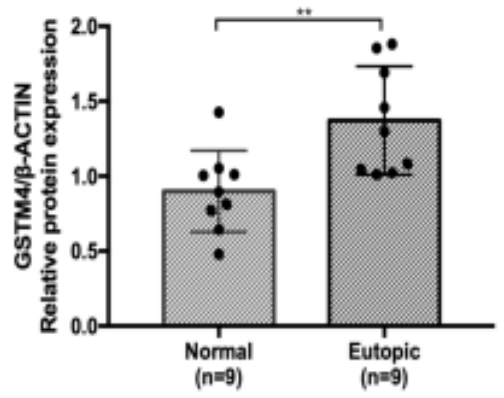

Figure 1

GSTM4 expression in endometriosis endometrial stromal cells from endometriosis patients compared to that from controls. (A) Representative immunohistochemical analysis of GSTM4 protein localization in normal endometrium and eutopic endometrium. Images were captured at magnififications of $\times 200$ (left panels) and $\times 400$ (right panels), respectively. (B) The immunohistochemical staining results were represented by optical density. (C) Representative western blots analysis of GSTM4 protein levels in normal endometrium, eutopic endometrium. $\beta$-Actin was used as a loading control. (D) Representative quantitative data of densitometric analyses. Data were presented as the mean \pm SD of three independent experiments. ( $\left.{ }^{*} \mathrm{P}<0.05 ;{ }^{*} \mathrm{P}<0.01 ;{ }^{*} \mathrm{P}<0.001\right)$. 
Figure 2

A

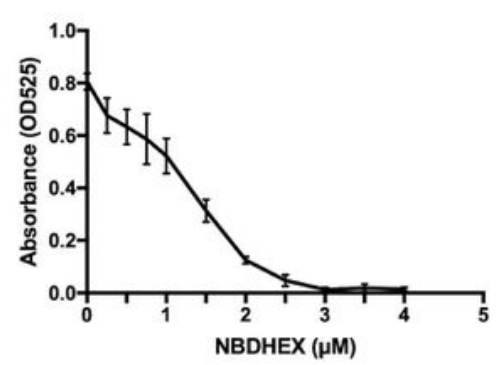

B

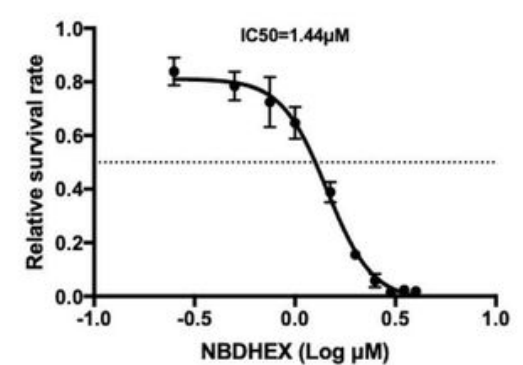

C
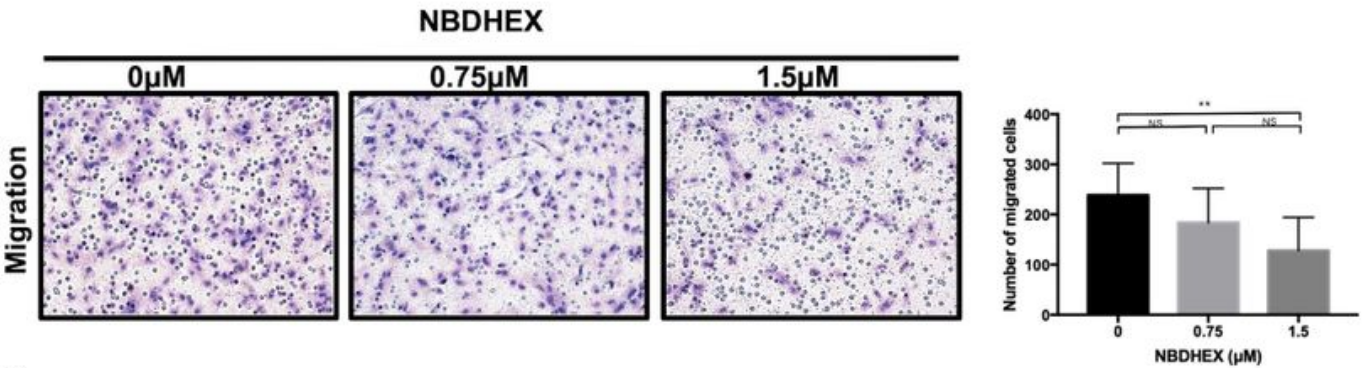

D
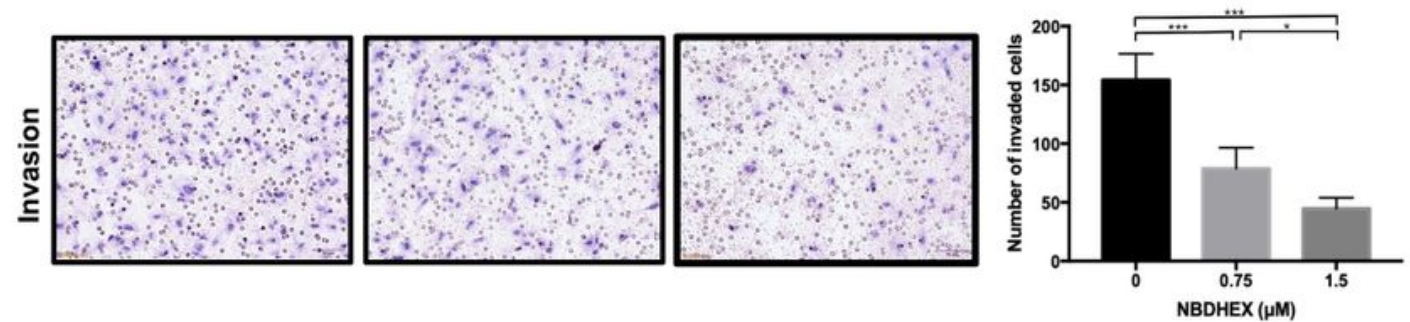

E
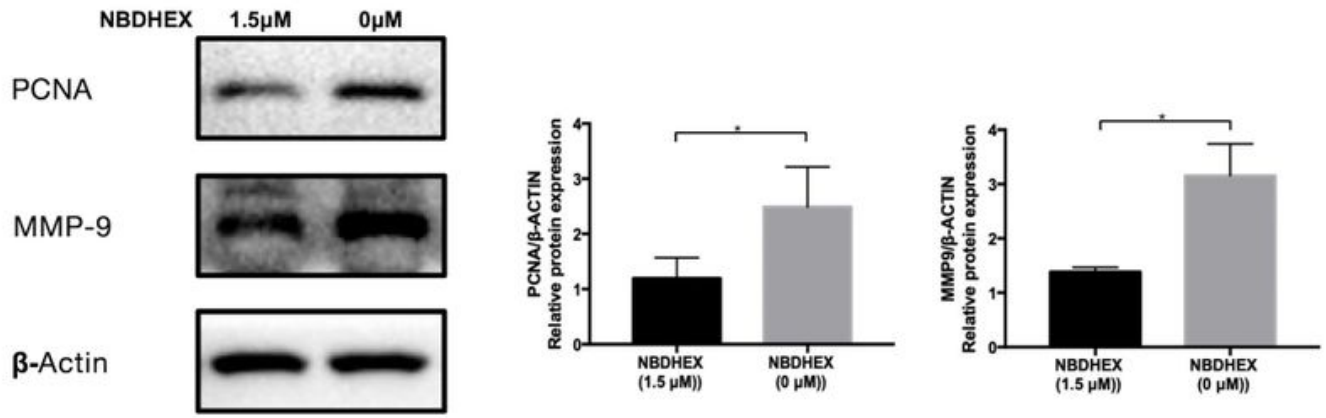

Figure 2

The GSTM4 inhibitor NBDHEX inhibits endometrial cells proliferation, migration and invasion. (A) NBDHEX inhibits endometrial cells growth in culture. Eutopic endometrial cells were treated with different doses of NBDHEX $(0.25 \mu \mathrm{M}, 0.5 \mu \mathrm{M}, 0.75 \mu \mathrm{M}, 1 \mu \mathrm{M}, 1.5 \mu \mathrm{M}, 2 \mu \mathrm{M}, 2.5 \mu \mathrm{M}, 3 \mu \mathrm{M}, 3.5 \mu \mathrm{M}$ and $4 \mu \mathrm{M})$. Cell proliferation was assessed by CCK8 assays. (B) The IC50 values of NBDHEX in endometrial cells was presented. (C) and (D) Eutopic endometrial stroma cells were treated with increasing concentrations of 
NBDHEX for cell migration (C) and invasion (D) assays using a transwell system. (E) Protein levels of PCNA and MMP-9 were determined by Western Blot. $\beta$-Actin was utilized for an endogenous reference to standardize protein levels. Densitometry analysis was carried out and normalized to $\beta$-Actin. Data were presented as the mean \pm SD of three independent experiments. $\left({ }^{*} P<0.05 ; * * P<0.01 ; * P<0.001, p>0.05\right.$ no significant difference).

\section{Figure 3}

A

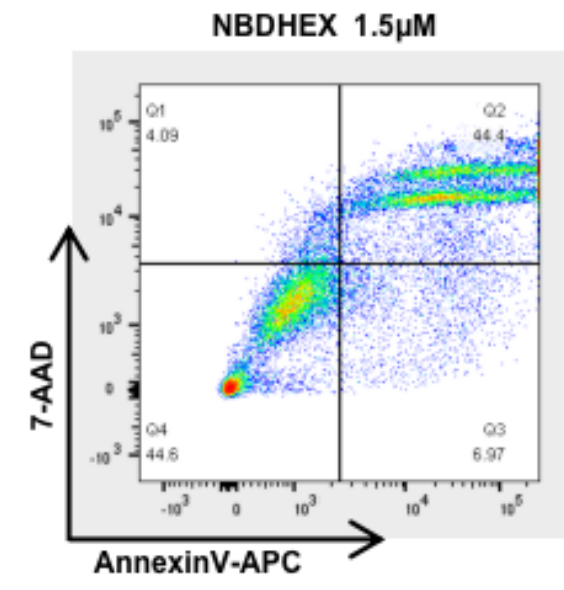

NBDHEX $1.5 \mu \mathrm{M}$

A

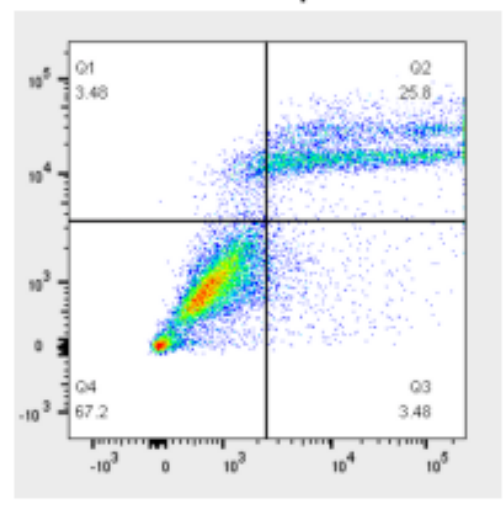

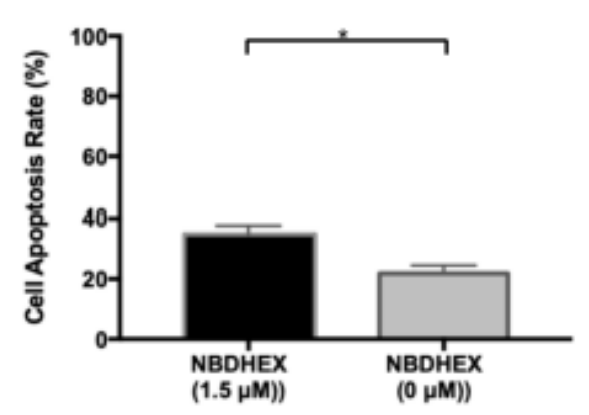

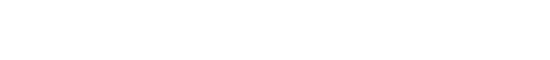

B

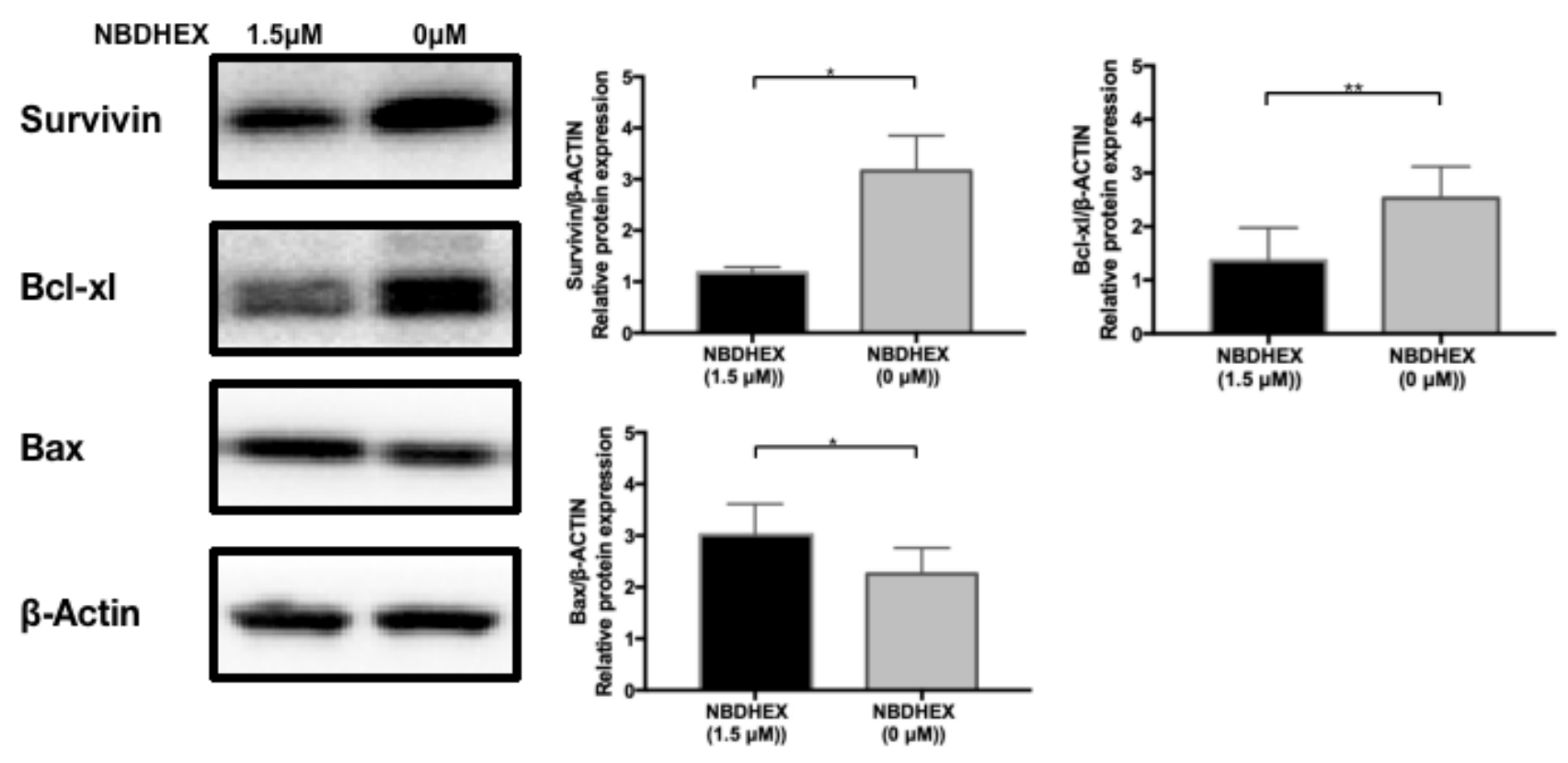

\section{Figure 3}

The GSTM4 inhibitor NBDHEX induces apoptosis in endometrial stromal cells from endometriosis patients. (A) The effect of NBEHEX on apoptosis in primary endometrial cells from endometriosis patients were detected by Annexin V-APC/7-AAD apoptosis kit. Graph represents \% cells undergoing apoptosis in two groups. (B) Changes in the protein level of Survivin, Bcl-xl and Bax in different groups 
detected by western blot analysis. Results are shown as mean \pm SD from three independent experiments. $(* \mathrm{P}<0.05 ; * * \mathrm{P}<0.01 ; * \mathrm{P}<0.001)$.

\section{Figure 4}

A
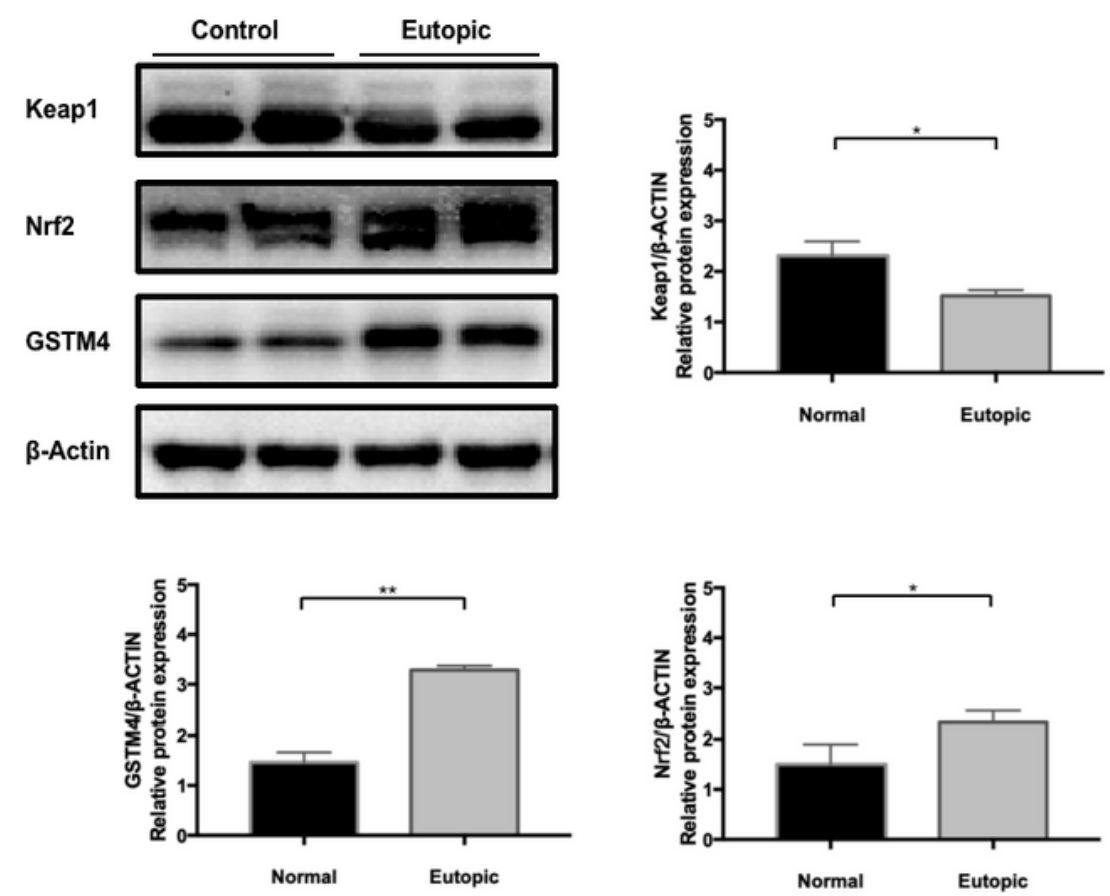

A
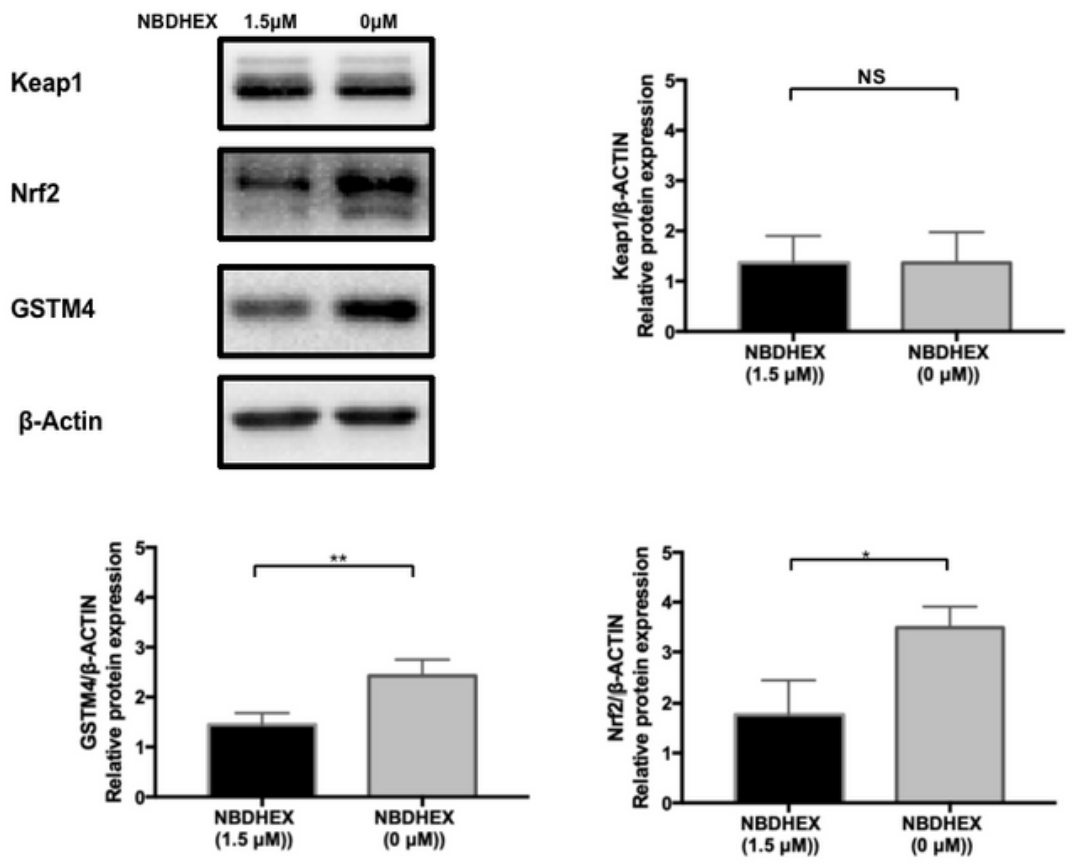

\section{Figure 4}

NBDHEX interacting with Nrf2 induced apoptosis in endometrial stromal cells from endometriosis patients. (A) Expression of Nrf2, Keap1, GSTM4 in endometrial cells compared with controls. (B) Effects of NBDHEX on Nrf2, Keap1 and GSTM4 in endometrial cells. All experiments were performed in triplicate. 
Data were presented as the mean \pm SD of three independent experiments. $\left({ }^{\star} P<0.05 ; * * P<0.01\right.$; ${ }^{*} P<$ $0.001, p>0.05$ no significant difference).

\section{Figure 5}

A
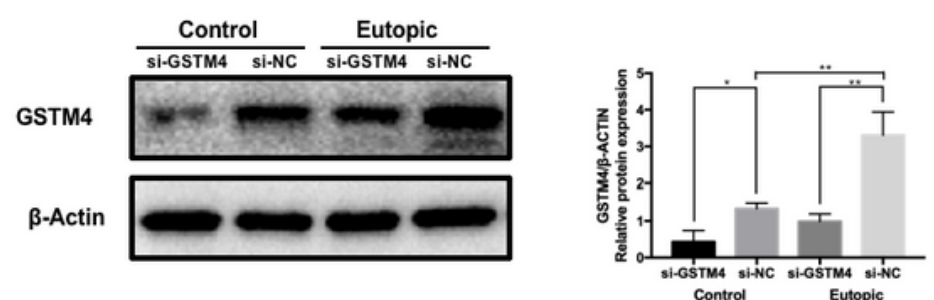

B

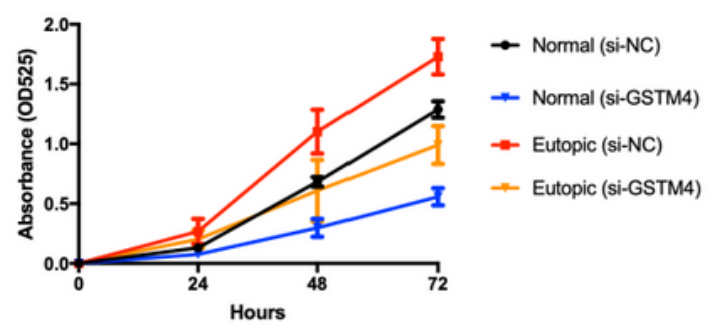

C
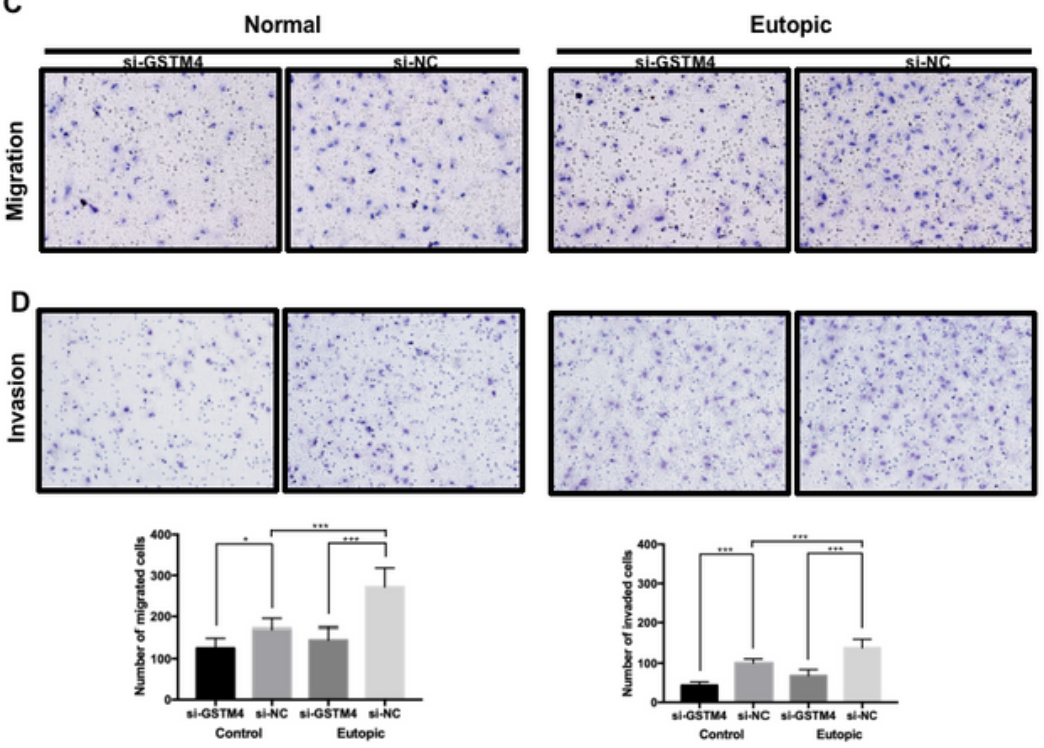

E
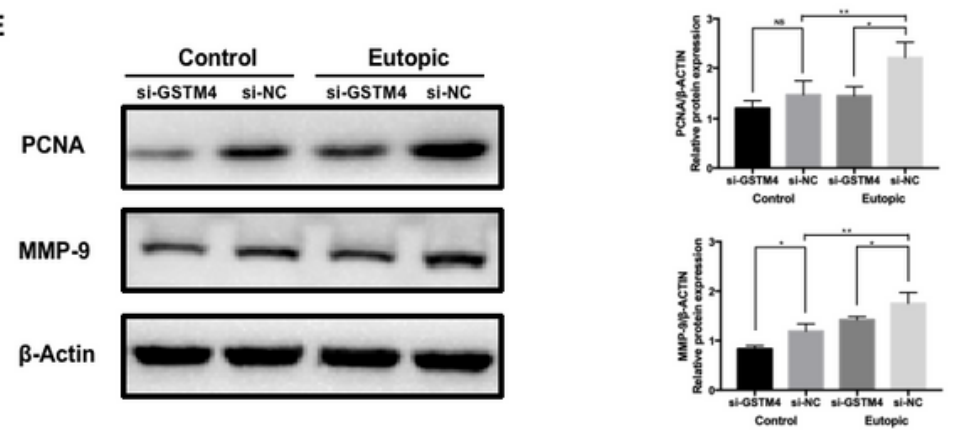

Figure 5

Knockdown of GSTM4 depress proliferation, migration, invasion and gene expression both in endometriosis and controls. (A) Knockdown of GSTM4 was demonstrated to reduce its protein expression level in endometrial cells and normal endometrial cells were detected by Western Blot, and $\beta$ - 
Actin used as a control. (B) Effect of GSTM4 knockdown on proliferation capacity of cells were detected by CCK-8 assay. (C) and (D) Endometrial cells and normal endometrial cells were transfected with siGSTM4, si-NC was the control. The cells were used for determining migration (C) and invasion (D) by using a transwell system. (E) Protein levels of PCNA and MMP-9 were determined by Western Blot, and $\beta$ Actin used as a control. Data were calculated as means \pm SD from at least three independent experiments. ( ${ }^{*}<<0.05 ; * * P<0.01 ; * P<0.001, p>0.05$ no significant difference).

Figure 6

A

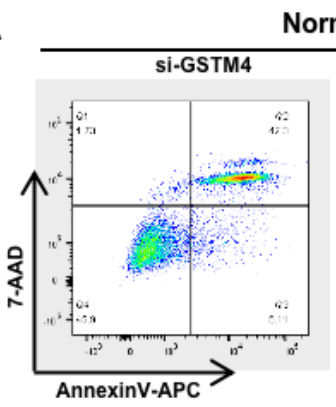

Normal
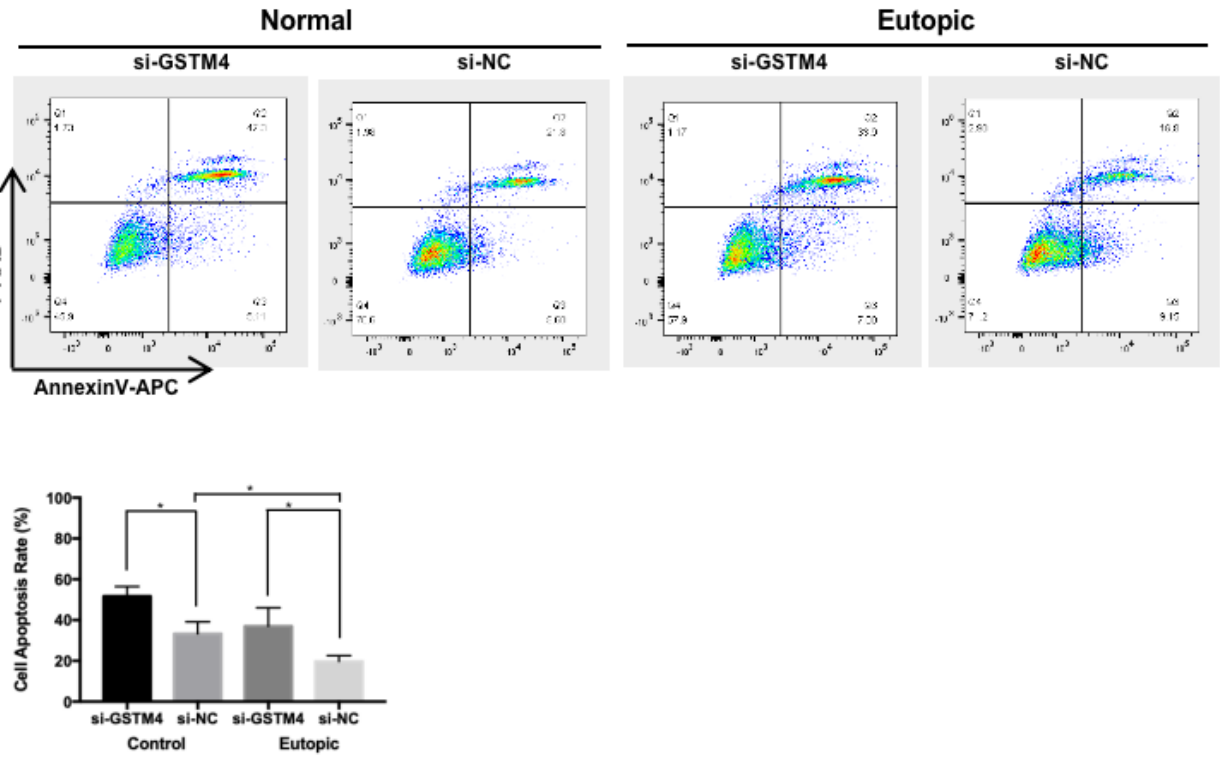

B

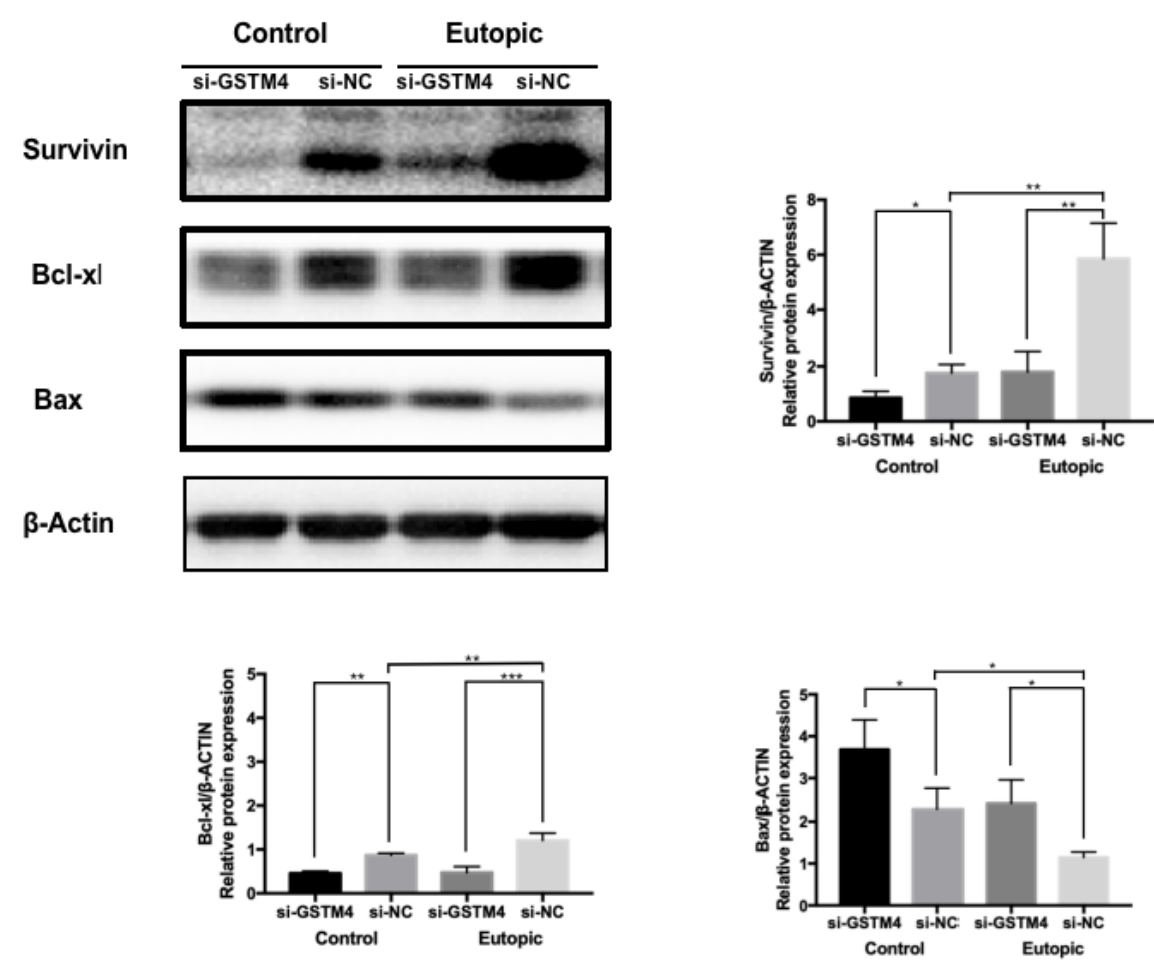

Figure 6 
GSTM4 Knockdown induced apoptosis both in endometriosis and controls. (A)The effect of GSTM4 Knockdown on apoptosis were detected by Annexin V-APC/7-AAD apoptosis kit. Graph represents \% cells undergoing apoptosis. (B) Changes in the expression of Survivin, Bcl-xl and Bax protein in different groups were detected by western blot analysis, and $\beta$-Actin used as a control. Data were calculated as means \pm SD from at least three independent experiments. ( $\left.{ }^{*}<<0.05 ;{ }^{*} P<0.01 ; * P<0.001\right)$.

\section{Figure 7}

A

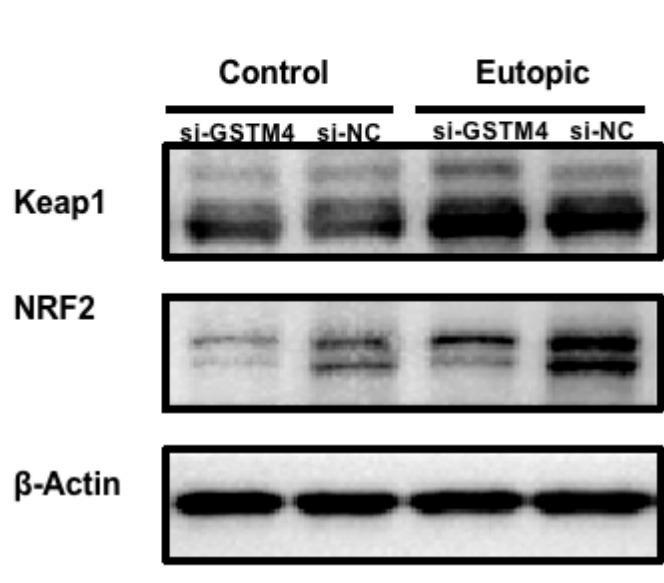

Control Eutopic
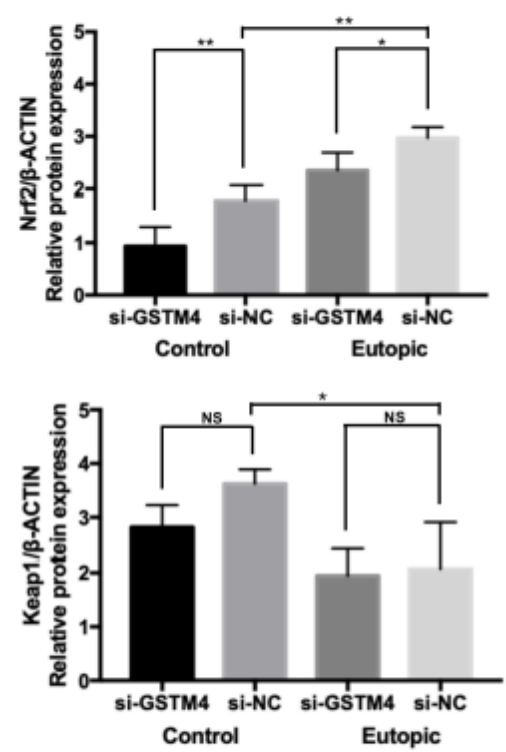

NRF2
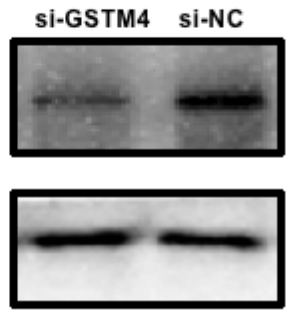

Lamin B1
Cytoplasm

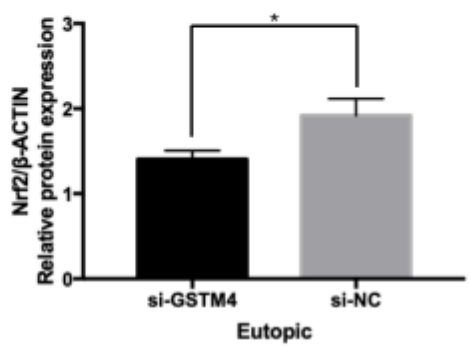

Cyteblast

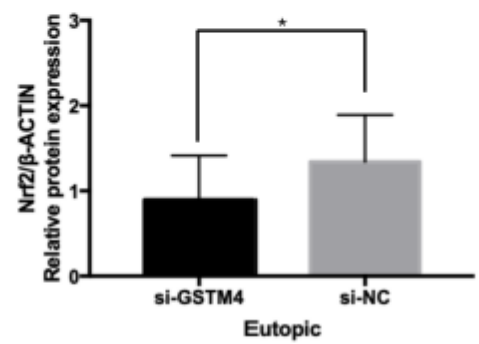

Figure 7 
Knockdown of GSTM4 interacting with Nrf2 induces apoptosis both in endometriosis and controls. (A) Expression of Nrf2, KEAP1, GSTM4 in in different groups. (B) Effects of GSTM4 Knockdown on Nrf2 both in nucleus and total cells. All experiments were performed in triplicate. Results are shown as mean \pm SD from three independent experiments. ( ${ }^{*} P<0.05 ;{ }^{*} \mathrm{P}<0.01 ;{ }^{*} \mathrm{P}<0.001, \mathrm{p}>0.05$ no significant difference).

\section{Figure 8}

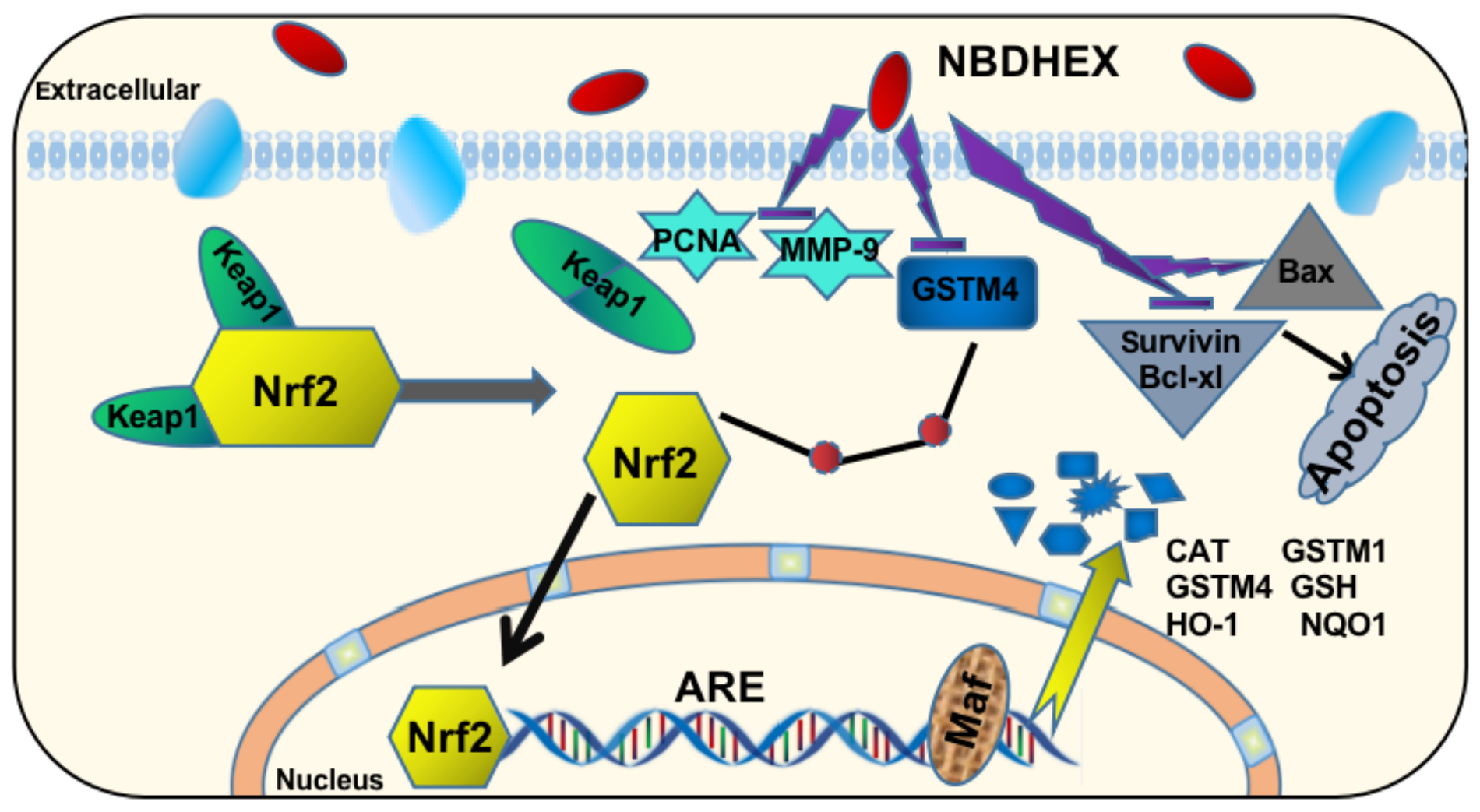

Figure 8

Mechanisms by which NBDHEX ameliorates the progression of endometriosis by regulating GSTM4 expression. 